\title{
Evaluating the potential impact of fishing on demersal species in the Bay of Biscay using simulations and survey data
}

\author{
David Ravard, Anik Brind'Amour*, Verena M. Trenkel
}

Ifremer, rue de l'île d'Yeu, BP 2011, 44311 Nantes cedex 03, France

*: Corresponding author: Anik Brind'Amour, tel.: +33 240374160 ; fax: +332 40374175 ; email address :

Anik.Brindamour@ifremer.fr

\begin{abstract}
:
Fishing affects fish populations through direct and indirect effects. It can change size structures and/or modify population mean weights. Reference values are thus needed to assess the status of populations in exploited ecosystems. These reference values can either be set by a historical approach, i.e. using information from before the onset of exploitation or overexploitation, or by a simulation approach. Using a model based on life-history parameters, we predicted population mean weights and length structures at equilibrium (in the absence of fishing and for fishing equal to different fishing mortalities) which we compared with contemporary data collected during scientific surveys in the Bay of Biscay. Contemporary mean weights were $88 \%$ to $30 \%$ smaller than expected for unexploited populations for 10 out of the selected 18 demersal species. Part of this difference might be explained by the survey not covering all age classes in the population, as demonstrated for Merluccius merluccius. We found that species with larger asymptotic length and slower growth were generally more impacted by fishing than smaller, faster growing species. Assuming that species specific life-history traits are well documented and/or easily measurable, the simulation approach can provide a useful tool for setting indicator reference levels for mean weight and size structures.
\end{abstract}

\section{Highlights}

The study provides an evaluation of the potential impact of fishing in the Bay of Biscay. It compares simulated and contemporary mean weights for 18 fish populations. Contemporary mean weights were $88 \%$ to $30 \%$ smaller.

Keywords: Indicators ; Fishing impacts ; Ecosystem based management ; Fish community ; Reference points ; Northeast Atlantic 


\section{Introduction}

The abundance of marine fish populations changes over time, both at local and global scales. Human activities play an important role in these variations, notably through overexploitation (Lotze and Worm, 2009), and anthropogenic-induced climate change (Hoegh-Guldberg and Bruno, 2010). Recent analyses of fishing impacts on life-history traits may underestimate the extent of these changes because (i) certain life history traits make some populations more resistant than others to fishing pressure, so that the relative short time spans of scientific surveys may not be long enough to observe these changes (Andersen and Brander, 2009); (ii) the analyses are mostly based on time series that started after the beginning and the acceleration of exploitation, which leads to a shift in the baseline used for assessments (Pauly, 1995); (iii) very few areas are not impacted by human activities which makes it unlikely to find an area of reference to set the baseline (Jackson et al., 2001).

One method to assess the impact of fishing on marine populations is to use indicators describing the studied system (Jennings, 2005). A wide range of indicators are known to describe the fisheries-induced changes in exploited populations and communities (Rochet and Trenkel, 2003; Fulton et al., 2005; Jennings, 2005; Shin et al., 2005). At the population level, impacts of fishing can either be direct: fisheries remove the oldest, largest individuals from the exploited populations (Rochet and Trenkel, 2003), or indirect: genetic selection driven by fishing affects growth rates, age- and size-at-maturation and reproductive output (Andersen and Brander, 2009). At the community level, there are potential indirect effects through habitat modification and/or food web propagation (Hiddink et al., 2011). Depletion of the largest species tends to release predation pressure which can result in a better survival of small species (Shin et al., 2005). 
Reference values are needed to assess population and ecosystem status using indicators. These reference values can either be set by a historical approach, i.e. using information collected before the onset of overexploitation (Lotze and Worm, 2009), or by simulating population structures in the absence of fishing (Jennings and Blanchard, 2004). Both methods do not necessarily give the same results, as in simulation studies current environmental conditions are generally assumed while historical data were probably collected under different environmental conditions. This can lead to confounding of the effects of fishing and those caused by environmental change (Jennings and Blanchard, 2004). Simulating populations at equilibrium assuming constant recruitment means that only mortality determines population structure. If the assumed mortality corresponds to natural mortality, the simulated mean weights and sizes provide reference values for evaluating the combined direct and indirect effects of fishing on exploited populations. Studying indirect effects on non target species is a necessary step towards ecosystem-based fisheries management which requires knowledge of the relationships between the different species and compartments of the system (Hall and Mainprize, 2004).

The Bay of Biscay has been exploited for a long time, making fishing the human activity with the most widespread impact (Lorance et al., 2009). This impact persists on both the population and community level (Rochet et al., 2005). A strong increase in fishing effort occurred in the late $19^{\text {th }}$ century when steam trawlers replaced sailing boats (Quéro and Cendrero, 1996). Historical documents show that some species such as large elasmobranches were already impacted at that time, and the increase of fishing effort combined with the industrialisation of fishing activities conducted to further depletion of some species. Historically, groundfishes represented most of the target species, as bottom trawls were the principal gears used in the Bay of Biscay (Quéro and Cendrero, 1996). More than a century later in the early 2000s, landings of small pelagic species such as sardine and anchovy were 
the most important in weight for French vessels, but a large number of groundfish species were still landed in substantial amounts, caught by a diversity of fishing gears (Daurès et al., 2009). Though French fleet size has decreased over the last decades as the result of vessel decommissioning programs aimed at reducing overcapacity, the expected positive effects for all exploited populations have not been observed (Rochet et al., 2012). Regarding environmental conditions, water temperatures have increased in the Bay of Biscay over the second half of the 20th century by on average $0.2^{\circ} \mathrm{C}$ per decade (Michel et al., 2009). This might have impacted the ecosystem on several levels; improved growth conditions are compatible with the food web changes observed by Rochet et al. (2010).

Here we study the potential impact of fishing on several groundfish stocks in the Bay of Biscay by comparing mean equilibrium weight and size distribution of simulated populations with those derived from survey data. The results are then discussed at the scale of populations and the assemblage, bearing in mind the possible short comings of survey data.

\section{Material and Methods}

Two types of data were used: (i) scientific survey data for the calculation of contemporary mean weights of exploited populations and (ii) life history parameters for the estimation of the mean weight for simulated populations.

\subsection{Survey data collection}

The data were collected during the scientific survey EVHOE. Survey data for the period 1987 to 2009 were used. They were collected annually in autumn between $43.7^{\circ} \mathrm{N}$ and $47.9^{\circ} \mathrm{N}$ using a stratified random sampling design. The data covered a relatively wide bathymetric range (15 - 623 m; Figure 1). The sampling gear was a GOV trawl 36/47 with 4 m vertical opening, $20 \mathrm{~m}$ horizontal opening and a mesh size of $20 \mathrm{~mm}$ in the codend. For each haul, 
115 individuals were identified, counted, weighed and measured to the lower centimetre. A total

116 of eighteen demersal species were selected for this study (Table 1). Length restrictions were

117 applied to account for the size-selectivity of the gear (see section 2.3.3 for details). It is worth

118 mentioning that not all species are commercially targeted.

$119 \quad 2.2 \quad$ Estimating mean weight

$120 \quad$ 2.2.1 Mean weight from simulated populations

121 For each species, estimates of mean weight in the absence of exploitation were obtained in

122 several steps. First, adult (at maturation) natural mortality $M$ in the absence of fishing was

123 estimated from life history parameters using the equation by Andersen et al. (2009)

$$
M=3(\Phi / \alpha) \eta^{-1 / 3} K
$$

125 with $\Phi$ the geometric factor of the predation size selection function, $\alpha$ the assimilation

126 efficiency of standard metabolism, $\eta$ the size at maturation divided by the asymptotic size

127 and $K$ the growth parameter of the von Bertalanffy growth function. For this study, $\Phi$ was set

128 to 0.12 (Andersen et al., 2009) and $\alpha$ to 0.8 for all species as most of the selected species are

129 carnivorous with a relatively high assimilation efficiency (Bodiguel et al., 2009; Freitas et al.,

130 2010; Winberg, 1956). The species specific parameters were either measured on the surveys

131 or taken from published studies for the Bay of Biscay (Table 2). We also computed $M$ values

132 scaling with individual body size using the empirical model developed by Gislason et al.

133 (2010). As the two models gave similar results, we only show those using the Andersen et al

134 model but we briefly discuss the results from both models in the discussion.

135 Second, population age-structure at equilibrium (numbers-at-age $N(a)$ ) was simulated

136 assuming constant recruitment $R$ 


$$
N(a+1)=N(a) \exp (-M) \quad a>0
$$

139 In practice, simulations were performed with a time increment of 0.1 years and ran for 500

140 years with recruitment fixed at one million individuals. This means that age $a$ had a resolution

141 of 0.1 years. The equilibrium state was verified by comparing the last simulation to the 50

142 preceding years.

143 Third, age was transformed into length-at-age $L(a)$ using the von Bertalanffy growth equation

$$
L(a)=L_{\text {inf }}(1-\exp (-K(a-t 0))) \quad[3]
$$

145 and the $K$ and $L_{\text {inf }}$ values in table 2 ; $t 0$ had to be set to 0 as it was missing for most species.

146 The appropriateness of the growth function values for the Bay of Biscay was verified by

147 comparing visually the position of the first peak in the length frequency distribution of the

148 survey data with the expected (fractional) age at the time of the survey for the youngest age

149 class caught by the survey (often young-of-the-year).

150 Fourth, length-at-age $L(a)$ was transformed into weight-at-age $W(a)$ using the length-weight

151 relationship

152

$$
\mathrm{W}(a)=\alpha L(a)^{\beta}
$$

153 with values for the coefficients $\alpha$ and $\beta$ taken from the literature (Table 2).

154 Fifth, unexploited mean weight $\bar{W}_{M}$ was estimated using the equilibrium numbers-at-age and 155 the calculated weight-at-age

$$
\bar{W}_{M}=(\Sigma S N(a) W(a)) /(\Sigma S N(a))
$$


157 To account for the length $L_{\mathrm{s}}$ at which the species could be assumed fully available to a given

158 survey, the selectivity indicator variable $S$ was set to zero for $L(\mathrm{a})<L_{\mathrm{s}}$. The way $L_{\mathrm{s}}$ was estimated is described in section 2.2.3.

Finally, for interpreting the survey derived mean weight values, simulations assuming a total

161 fishing mortality $Z=F+M$ varying from $1 M$ to $5 \mathrm{M}$ (steps of $0.5 \mathrm{M}$ ) were carried out. The

162 scenario in which $\mathrm{Z}=2 M$ is presented in detail with the simulated mean weight values

163 referred to as $\bar{W}_{2 M}$.

\subsubsection{Mean weight from survey data}

165 For survey data mean weight across all years $y$ was calculated using a per station approach

166 (Cotter, 2009) as the length of individual fishes captured in the same trawl are generally not

167 independent, in particular for schooling species. For this calculation individual length in

168 station $i$ was transformed into weight using the length-weight relation in eq. [4], this was

169 multiplied by the number of individuals in that length class $N_{\mathrm{i}}(\mathrm{l})$ to obtain the total weight-at-

170 length $W_{\mathrm{i}}(\mathrm{l})$. These weight-at-length were summed across length classes to obtain the total

171 weight $W_{\mathrm{i}}$ at station $i$. To take account of survey selectivity only individuals with length $\mathrm{l}>L_{\mathrm{s}}$

172 were included in the summation using as for the simulations the indicator variable $S$ (see

173 section 2.2.3). The estimators of mean survey weight $\bar{W}_{\text {surv }}$ and its variance are then

$$
\bar{W}_{\text {surv }}=\frac{\sum_{i}^{m}\left(\sum_{l} S W_{i}(l) / \sum_{l} N_{i}(l)\right)}{m}=\frac{\sum_{i}^{m} \bar{W}_{i}}{m}
$$

175

$$
\operatorname{Var}\left(\bar{W}_{\text {surv }}\right)=\sum_{i}^{m}\left(\bar{W}_{i}-\bar{W}_{\text {surv }}\right)^{2} /(m(m-1))
$$


with $\bar{W}_{i}$ the mean weight per station (for individuals larger than $L_{\mathrm{s}}$ ) and $m$ the total number of stations. Approximate 95\% confidence intervals were constructed assuming normality:

$\bar{W}_{\text {surv }} \pm 2 \sqrt{\operatorname{Var}\left(\bar{W}_{\text {surv }}\right)}$.

The data were pooled across all years to smooth interannual variations (see time series in Fig. S1 in electronic supplementary material).

\subsubsection{Survey selectivity determination}

To compare simulated mean weights with survey derived mean weights, the length at which a species was fully selected by the survey $\left(L_{\mathrm{s}}\right)$ was estimated to create the indicator variable $S$ used in equations [5] and [6]. Survey selectivity is defined here as a species catchability availability, catchability being caused by net selectivity, i.e. small individuals not being caught, and availability by juvenile habitats not covered by the survey, e.g. because they are in too shallow waters. The potential case of large individuals not being covered by the survey was only considered for M. merluccius (see below).

Length-frequency distributions cumulated across all years were inspected to select $L_{\mathrm{S}}$ values for all species (Table 1). Most of the length-frequency distributions were multimodal, with young-of-the-year (all individuals before the dotted vertical line in Fig. S2 in electronic supplementary material) showing a first normal-like distribution. This pattern was found for 14 out of the 18 selected species. In case of the four remaining species, juveniles were too small (L. whiffiagonisea) or not at all present (C. conger, D. labrax) or no clear mode was visible (S. canicula) (Fig. S3 in electronic supplementary material). The $L_{S}$ values were chosen to take into consideration these specificities. For the first group of species $L_{S}$ was set at relative small sizes (between 7 and $14 \mathrm{~cm}$ ), which in most cases corresponds to young-ofthe-year or age 1 . For the remaining species $L_{S}$ was selected so that only individuals from age 
199

2 and older were considered in the estimation of mean weight from the simulated populations and survey data (Fig. S2 and S3 in electronic supplementary material).

For M. merluccius a selectivity curve was available from the stock assessment model fitted by Bertignac et al. (2012). This selectivity curve had a dome shaped form. It was applied instead the cut off limit $L_{\mathrm{s}}$ to evaluate the reduced survey availability of both smaller and larger individuals.

\subsubsection{Comparing mean weights}

Simulated mean weights $\bar{W}_{M}$ were compared with the contemporary survey derived mean weights $\bar{W}_{\text {surv }}$ using the relative percentage difference

$$
\Delta \bar{W}_{\text {surv }-M}=100\left(\bar{W}_{\text {surv }}-\bar{W}_{M}\right) / \bar{W}_{M}
$$

Thus, negative values indicate that the contemporary mean values were smaller compared to those simulated assuming no fishing mortality. Relative percentage differences were also calculated using the mean weights obtained from the upper ( $\left.\bar{W}_{\text {surv }}^{u}\right)$ and lower $\left(\bar{W}_{\text {surv }}^{\text {low }}\right) 95 \%$ confidence intervals as well as the uncertainty analysis (section 2.2.5). To gauge the impact fishing might have had on contemporary fish populations we also compared the simulated $\bar{W}_{2 M}$ to simulated mean weights without fishing $\bar{W}_{M}$, referred to as $\Delta \bar{W}_{2 M-M}$.

To try and explain species differences, the species-specific $\Delta \bar{W}_{\text {surv }-M}$ values were regressed against two explanatory life history traits, $K$ and $L_{\text {inf, }}$ using linear quantile regression (QR). The lower 25\% quantile was modelled in the QR as it is expected that high $K$ make species more resilient to fishing impacts (less resilient for high $L_{\mathrm{inf}}$ ), which in turn should lead to less negative values, i.e. a positive relationship between $\Delta \bar{W}_{\text {surv-M }}$ and $K$ (negative relationship 
with $\left.L_{\text {inf }}\right)$. Further, ANOVA and boxplots were performed in order to test the effects of five

221 categorical explanatory variables: existence of a fishing quota (TAC) in the Bay of Biscay, 222 body shape of the species, magnitude of French landings, biogeography, and maximum depth 223 (Table 3).

\subsubsection{Calculating uncertainty intervals}

225 Uncertainty intervals incorporating parameter and sampling uncertainty into mean weight estimates and subsequently relative differences were constructed based on the most extreme

227 mean values obtained for a set of scenarios.

228 For simulated mean weights $\left(\bar{W}_{M}\right)$, in scenario $1,10 \%$ was added and removed from the $M$

229 values calculated with eq. (1), giving estimates $\bar{W}_{90 \% M}$ and $\bar{W}_{110 \% M}$. In scenario 2, $10 \%$ was

230 added and removed from $L_{\mathrm{S}}$ values (Table 1) used for creating the indicator variable $S$ (eq. 5),

231 giving $\bar{W}_{M, 90 \% L s}$ and $\bar{W}_{M, 110 \% L s}$ estimates. The lower uncertainty value is then $\bar{W}_{M}^{\text {low }}=\min ($

$\left.232 \bar{W}_{110 \% M}, \bar{W}_{M, 90 \% L s}\right)$ and the upper one $\bar{W}_{M}^{u p}=\max \left(\bar{W}_{90 \% M}, \bar{W}_{M, 110 \% L s}\right)$. The same approach was 233 applied for $\bar{W}_{2 M}$.

234 For survey mean weights ( $\left.\bar{W}_{\text {surv }}\right)$, 10\% was added and removed from $L_{\mathrm{S}}$ values and

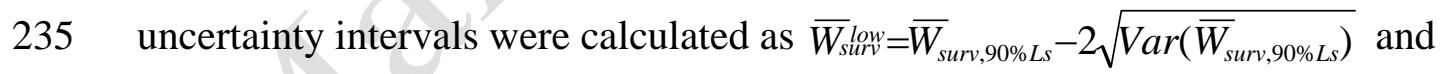

$236 \quad \bar{W}_{\text {surv }}^{u p}=\bar{W}_{\text {surv }, 110 \% L s}+2 \sqrt{\operatorname{Var}\left(\bar{W}_{\text {surv }, 110 \% L s}\right)}$.

237 Similarly, uncertainty intervals for relative differences in mean weight were obtained as

$238 \Delta \bar{W}_{\text {surv }-M}^{\text {low }}=f\left(\bar{W}_{\text {surv }}^{\text {up }}, \bar{W}_{M}^{\text {low }}\right)$ and $\Delta \bar{W}_{\text {surv }-M}^{\text {up }}=f\left(\bar{W}_{\text {surv }}^{\text {low }}, \bar{W}_{M}^{\text {up }}\right)$. 


\section{Results}

\subsection{Comparing mean weights}

241 Simulations were carried out for the five different $\mathrm{F}$ values ( $\mathrm{F}=1 \mathrm{M}$ to $5 \mathrm{M}$ ). For $40 \%$ of the

242 studied species, the scenario using $\mathrm{F}=\mathrm{M}$ provided the best match between simulated and

243 contemporary mean weights (Figure 2). In contrast, for Conger conger, Chelidonichthys

244 cuculus, Physis blennoides, and M. merluccius values as high as 2.5M and 3M provided the

245 best agreement.

246 When considered in details, the relative difference between simulated and survey-derived

247 mean weight estimates $\Delta \bar{W}_{\text {surv-M }}$ was negative or close to zero for all 18 species (dark grey

248 bars in Figure 3). Uncertainty intervals increased with relative differences. The ten species

249 showing the largest relative difference in mean weight were: $C$. conger, $M$. merluccius, $L$.

250 piscatorius, C. cuculus, P. blennoides, Trachurus trachurus, Mullus surmuletus, Callionymus

251 lyra, Solea solea and Lophius budegassa with mean relative differences ranging from -88\% to

$252-30 \%$ (Figure 3). The largest relative difference in mean weight was found for C. conger, for

253 which uncertainty intervals ranged from $-92 \%$ to $-83 \%$. Thus, this suggests that the

254 contemporary mean weight in the survey is substantially smaller than would be expected in an

255 unexploited population. On the second rank, contemporary M. merluccius mean weights were

$25683 \%$ to 89\% smaller. However, results for C. Conger and M. merluccius might partly be due

257 to larger individuals not having been available to the survey. When using the dome-shaped

258 selectivity curve, available for M. Merluccius, the relative mean weight uncertainty interval

259 was reduced to $-46 \%$ to $-16 \%$ (filled circle with whiskers in Figure 3). L. piscatorius and C.

260 cuculus ranked third and fourth, with contemporary mean weights being $52 \%$ to $72 \%$, and

$26147 \%$ to $69 \%$ smaller than expected mean weights in the absence of exploitation. The species

262 showing no difference, i.e. where the uncertainty interval included zero were: Trisopterus 
luscus, Dicentrarchus labrax, Merlangius merlangus, Lepidorhombus whiffiagonis, Scyliorhinus canicula and Dicologlossa cuneata. That means that the mean weights under exploitation were almost the same or even slightly larger (for D. cuneata) than mean weights simulated without exploitation (dark grey bars in Figure 3).

Looking at the comparison between length-frequency distributions in the survey data representing contemporary exploited populations and in the populations simulated with no fishing, three patterns emerge (light grey bars in Figure 4): (i) small individuals are very abundant while the larger ones are quickly eroded in the contemporary populations; (ii) the mode of the length structure is located on small length classes but larger individuals persist in the contemporary population with lower number than in the simulations; (iii) there is no difference between the size classes of the contemporary population and the simulated ones. The five species with the largest relative differences in mean weight (C. conger, $M$. merluccius, L. piscatorius, C. cuculus and P. blennoides) all showed the first pattern, though this is less pronounced for C. cuculus and P. blennoides, possibly because the two species reach a smaller asymptotic size. Presence of larger size classes but in lower abundance was characteristic for M. surmuletus, L. budegassa, and C. gurnardus. The four species with the smallest relative difference in mean weight exhibited no difference in the survey and simulated size classes (D. labrax, L. whiffiagonis and S. canicula). D. cuneata displayed a specific pattern, with the mode close to the asymptotic size. Unexpectedly, M. merlangius showed pattern (i). These length structures, combined with the species specific weight-atlength were largely in agreement with the observed relative differences in mean weight $\Delta \bar{W}$.

Turning to the comparison between the relative difference in mean weight for simulations with and without fishing mortality ( $\Delta \bar{W}_{2 M-M}$, white bars in Figure 3) and the relative differences discussed above for contemporary populations ( $\Delta \bar{W}_{\text {surv-M }}$, grey bars in Figure 3). 
Three different cases can be distinguished. In the first case, $\Delta \bar{W}_{\text {surv-M }}$ was larger than $\Delta \bar{W}_{2 M-M}$

288

289

290

291

292

293

294

295

296

297

298

299

300

301

302

303

304

305

306

307

308

(C. conger, C. cuculus, M. merluccius, and P. blennoides). This would indicate that these species might be exploited at fishing mortalities above $M$. In the second case, the two values were almost equal (L. piscatorius, C. gurnardus, C. lyra, S. solea and T. trachurus), compatible with contemporary fishing mortalities about equal to $M$. In the third case, $\Delta \bar{W}_{\text {surv-M }}$ was smaller than $\Delta \bar{W}_{2 M-M}$ (D. labrax, D. cuneata, L. whiffiagonis, L. budegassa, $M$. merlangus, M. surmuletus, S. canicula, T. luscus and Z. faber), which could indicate that contemporary fishing mortalities were below natural mortality. However, this interpretation is contingent on the survey covering the whole population and variations in recruitment averaging out over the twenty-three year time series. We will come back to this point in the discussion. Larger uncertainty intervals for $\Delta \bar{W}_{2 M-M}$ can be explained by the sensitivity to $M$. In other words the variability (10\%) on $M$ was applied twice as we compare both simulated populations.

\subsection{Explaining relative differences in mean weight}

The quantile regression showed that the lower 25\% quantile of $\Delta \bar{W}_{\text {surv-M }}$ increased, as expected, with growth rate $K$ and decreased with $L_{\text {inf }}$ even though the slopes were not significantly different from zero (Figure 5). These results seemed to be strongly influenced by C. conger as its asymptotic size is high compared to the other species considered. However, the same trends were found when this species was removed from the analysis, though the slopes were shallower (K: slope $=2.7$ instead of 3.07).

Looking at the categorical explanatory variables, the ANOVA found no significant differences between levels for all explanatory variables ( $p$-values $>0.1$ ) and no clear patterns 
emerged from the boxplots except for maximum depth. Relative differences in mean weight increased for species being distributed deeper (Figure 5).

\section{Discussion}

For size-based indicators such as mean weight, mean size or evolutionary indicators such as growth parameters or size-at-maturity, there is a clear need for historical or simulation-based studies to derive reference values. Contemporary survey data are considered unsuitable for setting reference values. This study confirms this view as the mean weights in the surveys showed a clear decrease in comparison to mean weight of simulated populations with no fishing. Similar results were found by Jennings and Blanchard (2004) at the community level for the North Sea. These authors demonstrated that mean weight of an individual in the community represented 38\% of that expected without fishing.

In this study all studied species showed some level of response to fishing, the larger species being the most impacted, as four out of the five most impacted species in terms of mean weight reduction were large species (C. conger, L. piscatorius, $M$. merluccius and $P$. blennoides). These results are consistent with many studies showing that larger individuals are usually more impacted by fishing (Bianchi et al., 2000; Jennings et al., 2002, 1999; Myers and Worm, 2003; Rogers and Ellis, 2000). Large species have low natural mortality, low fecundity and low growth rates and therefore have less chances of repopulating than smaller species with a high reproductive strategy and fast growth (Denney et al., 2002).

No clear differences were found between target and bycatch species. Indeed, several species displaying strong or medium response to fishing (C. cuculus and C. gurnardus, C. lyra) are not targeted by any fisheries but may represent large bycatches (Dubé et al., 2012). Dubé et al. (2012) estimated the bycatch rate for C. cuculus at over 18\% (in weight) for large bottom 
trawlers (> $18 \mathrm{~m}$ ) the Bay of Biscay in 2011. For this species and several other species, incidental fishing mortality is often the consequence of similar habitat requirements as target species. For instance, Triglidae and C. lyra, inhabit sandy, muddy or gravely grounds (Griffin et al., 2012; Marriott et al., 2010) which are also preferred by L. piscatorius (soft to hard sand and gravel substrata, (Fariña et al., 2008)), which is one of the target species.

For several species (incl. L. whiffiagonis and Z. faber), the simulated mean weights without fishing were about the same than contemporary mean weights, suggesting that these species might be either underexploited or not well sampled by the bottom trawl survey gear. The first interpretation is supported by the fact that the simulated size distributions were similar to the survey distributions. In contrast, the ICES stock assessment working group (WGHMM, 2008), considered $L$. whiffiagonis as being within or slightly outside safe biological limits in the Iberian region or northern Bay of Biscay, which supports the second interpretation.

Although their lower uncertainty interval spanning negative values does not allow for clear interpretation, two species, D. cuneata and S. canicula, were found to have slightly larger contemporary mean weights compared to those derived from simulations with no fishing. It is commonly assumed that the removal of top predators in a community should be beneficial for their preys (Daan et al., 2005; Shin et al., 2005), which could explain the result for $D$. cuneata, a small flatfish. Lesser spotted dogfish (S. canicula) has become more dominant in abundance among the elasmobranchs in British waters during the last century (Rogers and Ellis, 2000), which might imply a change in recruitment strength and thus explain smaller contemporary mean weight.

Other factors than fishing could explain the seemingly large differences in mean weight between contemporary and simulated populations: i) bias induced by the survey sampling protocol, ii) absence of size- or age-selective mortality in the model, and iii) environmental 
effects on growth. All of these will lead to overestimating mean weight differences between the surveys and the simulations. We will now discuss each issue in turn.

\subsection{Survey size selectivity and species catchability}

359 Survey data such as those used in this study are inevitably selective for specific size classes.

360 Smaller size classes may escape through the meshes or may be inhabiting shallower habitats than those surveyed whereas larger individuals or species (with a greater swimming ability) may rise up and escape from the GOV trawl (Main and Sangster, 1981). In the study the youngest individuals were removed from the calculations of mean weight for both the simulations and survey to account for smaller fish being underrepresented in the survey catches. A correction for any selectivity bias for larger size classes was however more difficult to apply due to the scarcity of GOV selectivity curves for the species included in our study. When we corrected for size selectivity on larger individuals of $M$. merluccius using the selectivity curve estimated by Bertignac et al. (2012), the difference in mean weight reduced

369 substantially. For this species not having sampled the larger individuals probably led to 370 overestimating the mean weight difference. C. conger displayed an excessively high response to fishing mortality. It is uncertain whether

372 or not this response is entirely due to fishing or to a low level of catchability during the 373 bottom trawl surveys. C. conger inhabits the continental shelf and the rocky shelf-slope areas, 374 where it displays a high degree of fidelity to obtain refuge in rocks (Xavier et al., 2010).

375 Rocky habitats are inadequately sampled using bottom trawls and this may thus explain, at 376 least partially, our results. 


\subsection{Modelling hypotheses}

378

379

380

381

382

383

384

385

386

387

388

389

390

391

392

393

394

395

396

397

398

399

The mean weight and size distributions obtained in our simulations depend on the life history parameter values and the underlying assumptions of the model for natural mortality (Andersen et al., 2009). A strong assumption of the model is the absence of size-selective natural mortality. Theoretical and empirical results suggest that natural mortality should scale with individual body size (Gislason et al., 2010). We computed natural mortality values using Gislason et al. empirical model and found the results highly similar to those of the Andersen et al. model (Spearman $\mathrm{r}=0.98, \mathrm{p}<0.01$ ). Thus, failing to consider size-selective natural mortality cannot explain the greater proportion of larger individuals in our simulations.

The natural mortality values used in this study (Table 2), did not necessarily agreed with those assumed in contemporary stock assessment models. For example, for $M$. merluccius we used $M=0.31$ while Bertignac et al. (2012) used $M=0.4$ for all sizes. Using the smaller value for $M$ in the simulations might have led to overestimating differences in mean weight. Another example is for $S$. solea where the natural mortality value found in the literature and used in this study ( $M=0.48)$ was larger than the one used by the ICES assessment group ( $M=0.1$; ICES 2012). In that case, using larger $M$ value for $S$. solea in the simulations might have led to underestimating differences in mean weight.

\subsection{Environment}

Among the expected responses of fish to climate change and the warming of waters is the deepening of large individuals and changes in species growth rates according to depth (Thresher et al. 2007). Macpherson and Duarte (1991) showed that large individuals migrate toward deeper waters during ontogeny where they physiologically benefit from lower temperature (lower metabolism). Using eight species displaying different depth ranges, 
Thresher et al. (2007) observed increased growth rate for species living above $250 \mathrm{~m}$ and the opposite trend for deeper species (i.e. below $250 \mathrm{~m}$ ). Slower growth rate may thus lead to lower mean weight. Observations of larger individuals inhabiting deeper habitats have been documented for L. piscatorius (Garcia-Rodriguez et al., 2005) and M. merluccius (Woillez et al., 2007).

Dulvy et al. (2008) highlighted that the North Sea winter bottom temperature has increased by $1.6^{\circ} \mathrm{C}$ over the last 25 years. During that period, the demersal fish assemblage deepened by $\sim 3.6 \mathrm{~m}^{\text {decade }}{ }^{-1}$. Warming trends in the Bay of Biscay in modelled and in situ temperatures were $0.23^{\circ} \mathrm{C}$ and $0.30^{\circ} \mathrm{C}$ decade ${ }^{-1}$ respectively (Huret et al. 2013, Michel et al. 2009). However, no changes in spatial distribution with bottom water temperature were found for any of the eight species studied by Persohn et al. (2009) in the Bay of Biscay, six of which were also part of this study. So changes in bottom temperature might have increased growth rates, which go in the direction of compensating fishing impacts rather than explain the estimated differences in mean weight.

The absence of explanatory power for most of the categorical variables can be explained by (i) the relatively low number of species and low diversity in life history traits among the selected species in this study, this low count being notably due to the fact that life-history trait parameters are not always easy to obtain for non commercial species, and (ii) that fishing sensitivity seems to be caused by multifactorial combinations rather than one dominant factor. Nevertheless, the shapes of the relationships between the difference in mean weight and maximum length $L_{\text {inf }}$ or maximum depth range, though not statistically significant), strengthen our conclusions regarding the effects of fishing on larger species. 


\section{Conclusion}

423 We showed that in the Bay of Biscay the demographic structure of most of the 18 selected

424 species seemed to be impacted by fishing, with the larger species displaying larger reduction

425 in mean weight. Using M. merluccius, we demonstrated the sensitivity of the results to the

426 assumed survey selectivity. While no clear differences between target and bycatch species

427 were found, it is important to note that two important commercial species in the Bay of

428 Biscay, $M$. merluccius and $L$. piscatorius, were among the top species with the largest relative

429 reduction in mean weight.

430 Assuming that the mortality in fish populations corresponded exclusively to natural mortality,

431 we obtained reference values for mean weights and sizes which are free from any effects of

432 fishing. Hence these simulated reference values can be used for setting limit reference points

433 but not target reference points for exploited populations. In contrast empirical contemporary

434 values already include the effects of fishing and are therefore unsuitable for setting reference 435 points.

$436 \quad 6$ Acknowledgement

437 The work by D.R. was funded by a PhD grant from the Pays de la Loire region and Ifremer.

$438 \quad 7 \quad$ References

439 Andersen, K.H., Brander, K., 2009. Expected rate of fisheries-induced evolution is slow.

440 Proc. Natl. Acad. Sci. 106, 11657-11660. 
441

442

443

444

445

446

447

448

449

450

451

452

453

454

455

456

457

458

459

460

461

462

Andersen, K.H., Farnsworth, K.D., Pedersen, M., Beyer, J.E., 2009. How community ecology

links natural mortality, growth, and production of fish populations. Ices J. Mar. Sci. 66, 19781984.

Bertignac, M., Fernández, C., Methot, R., 2012. Preliminary spatially disaggregated stock assessment of northern hake, a widely distributed stock of the north-east Atlantic. Ices Cm.

Bianchi, G., Gislason, H., Graham, K., Hill, L., Jin, X., Koranteng, K., Manickchand-

Heileman, S., Paya, I., Sainsbury, K., Sanchez, F., Zwanenburg, K., 2000. Impact of fishing on size composition and diversity of demersal fish communities. Ices J. Mar. Sci. 57, 558571.

Blanchard, F., Thebaud, O., Guyader, O., Lorance, P., Boucher, J., Chevaillier, P., 2001.

Effets de la pêche et du réchauffement climatique sur la coexistence spatiale des espèces de poissons du golfe de Gascogne. Conséquences pour les pêcheries (Rapport final projet de recherche), Biodiversité et changement global. IFREMER.

Bodiguel, X., Maury, O., Mellon-Duval, C., Roupsard, F., Le Guellec, A.-M., Loizeau, V., 2009. A dynamic and mechanistic model of PCB bioaccumulation in the European hake (Merluccius merluccius). J. Sea Res. 62, 124-134.

Casas, J.M., Piñeiro, C., 2000. Growth and age estimation of greater fork-beard (Phycis blennoides Bruènnich, 1768) in the north and northwest of the Iberian Peninsula (ICES Division VIIIc and IXa). Fish. Res. 47, 19-25.

Correia, A.T., Manso, S., Coimbra, J., 2009. Age, growth and reproductive biology of the European conger eel (Conger conger) from the Atlantic Iberian waters. Fish. Res. 99, 196202. 
463

464

465

466

467

468

469

470

471

472

473

474

475

476

477

478

479

480

481

482

Cotter, J., 2009. Statistical estimation of mean values of fish stock indicators from trawl surveys. Aquat. Living Resour. 22, 127-133.

Cubillos, L., Arancibia, H., 1995. Comparative growth performance of horse mackerle of the genus Trachurus, with emphasis on T. symmetricus murphyi in Chile. Sci. Mar. 59, 647-652.

Daan, N., Gislason, H., Pope, J.G., Rice, J.C., 2005. Changes in the North Sea fish community: evidence of indirect effects of fishing? Ices J. Mar. Sci. 62, 177-188.

Daurès, F., Rochet, M.-J., Van Iseghem, S., Trenkel, V.M., 2009. Fishing fleet typology, economic dependence, and species landing profiles of the French fleets in the Bay of Biscay, 2000-2006. Aquat. Living Resour. 22, 535-547.

Denney, N.H., Jennings, S., Reynolds, J.D., 2002. marine fishes Life-history correlates of maximum population growth rates in marine fishes. Proc. R. Soc. 269, 2229-2237.

Dorel, D., 1986. Poissons de l’Atlantique Nord-Est Relations tailles-poids.

Dorel, D., Cadiou, Y., Porcher, P., 1998. Poissons, crustacés et mollusques des mers communautaires. Paramètres biologiques et représentations graphiques. IFREMER.

Dubé, B., Diméet, J., Rochet, M.-J., Tétard, A., Gaudou, O., Messanot, C., Fauconnet, L., Morizur, Y., Biseau, A., Salaun, M., 2012. Observations à bord des navires de pêche professionnelle Bilan de l'échantillonnage 2011.

Dulvy, N.K., Rogers, S.I., Jennings, S., Stelzenmüller, V., Dye, S.R., Skjoldal, H.R., 2008.

Climate change and deepening of the North Sea fish assemblage: a biotic indicator of warming seas. J. Appl. Ecol. 45, 1029-1039. 
483 Fariña, A.C., Azevedo, M., Landa, J., Duarte, R., Sampedro, P., Costas, G., Torres, M.A., 484 Cañas, L., 2008. Lophius in the world: a synthesis on the common features and life strategies. 485 Ices J. Mar. Sci. 65, 1272-1280.

486 Félix, P.M., Vinagre, C., Cabral, H.N., 2011. Life-history traits of flatfish in the Northeast 487 Atlantic and Mediterranean Sea. J. Appl. Ichthyol. 27, 100-111.

488 Freitas, V., Cardoso, J.F.M.F., Lika, K., Peck, M.A., Campos, J., Kooijman, S.A.L.M., Van 489 der Veer, W., 2010. Temperature tolerance and energetics: a dynamic energy budget-based 490 comparison of North Atlantic marine species. Philos. Trans. R. Soc. 365, 3553-3565.

491 Fulton, E.A., Smith, A.D.M., Punt, A.E., 2005. Which ecological indicators can robustly 492 detect effects of fishing? Ices J. Mar. Sci. 62, 540-551.

493 Garcia-Rodriguez, M., Pereda, P., Landa, J., Esteban, A., 2005. On the biology and growth of 494 the anglerfish Lophius budegassa Spinola, 1807 in the Spanish Mediterranean: a preliminary 495 approach. Fish. Res. 71, 197-208.

496 Gislason, H., Daan, N., Rice, J.C., Pope, J.G., 2010. Size, growth, temperature and the natural 497 mortality of marine fish. Fish Fish. 11, 149-158.

498 Griffin, R., Pearce, B., Handy, R.D., 2012. Dietary preference and feeding selectivity of 499 common dragonet Callionymus lyra in U.K. J. Fish Biol. 81, 1019-1031.

500 Hall, S.J., Mainprize, B., 2004. Towards ecosystem-based fisheries management_. Fish Fish. $501 \quad 5,1-20$. 
502

503

504

505

506

507

508

509

510

511

512

513

514

515

516

517

Hiddink, J.G., Johnson, A.F., Kingham, R., Hinz, H., 2011. Population biology of the red gurnard (Aspitrigla cuculus L.; Triglidae) in the inshore waters of Eastern Anglesey and Northwest Wales. J. Appl. Ecol. 48, 1441-1449.

Hoegh-Guldberg, O., Bruno, J.F., 2010. The Impact of Climate Change on the World’s Marine Ecosystems. Science 328, 1523-1528.

ICES (2012). Bay of Biscay sole in ICES 2012 Report of the Working Group on the Assessment of Southern Shelf Demersal Stocks of Hake, Monk and Megrim, (WGHMM), 1016 May 2012, ICES Headquarters, Copenhagen. CIEM / ICES, Ref. ICES CM 2012/ACOM:11, pp. 103-145, 13p., 43p.Jackson, J.B.C., Kirby, M.X., Berger, W.H., Bjorndal, K.A., Botsford, L.W., Bourque, B.J., Bradbury, R.H., Cooke, R., Erlandson, J., Estes, J.A., 2001. Historical Overfishing and the Recent Collapse of Coastal Ecosystems. Science 293, 629-638.

Jennings, S., 2005. Indicators to support an ecosystem approach to fisheries. Fish Fish. 6, 212-232.

Jennings, S., Blanchard, J.L., 2004. Fish abundance with no fishing: predictions based on macroecological theory. J. Anim. Ecol. 73, 632-642.

Jennings, S., Greenstreet, S.P.R., Hill, L., Piet, G.J., Pinnegar, J.K., Warr, K.J., 2002. Longterm trends in the trophic structure of the North Sea fish community: evidence from stableisotope analysis, size-spectra and community metrics. Mar. Biol. 141, 1085-1097.

Jennings, S., Greenstreet, S.P.R., Reynolds, J.D., 1999. Structural change in an exploited fish community: a consequence of differential fishing effects on species with contrasting life histories. J. Anim. Ecol. 68, 617-627. 
525 Assessment of impacts from human activities on ecosystem components in the Bay of Biscay 526 in the early 1990s. Aquat. Living Resour. 22, 409-431.

527 Lotze, H.K., Worm, B., 2009. Historical baselines for large marine animals. Trends Ecol. 528 Evol. 24, 254-262.

529 Macpherson, E., Duarte, C.M., 1991. Bathymetric trends in demersal fish size: is there a 530 general relationship? Mar. Ecol. Prog. Ser. 71, 103-112.

531 Magnussen, E., 2007. Interpopulation comparison of growth patterns of 14 fish species on 532 Faroe Bank: are all fishes on the bank fast-growing? J. Fish Biol. 71, 453-475.

533 Mahé, K., Delpech, J.-P., Carpentier, A., 2006. Synthèse bibliographique des principales 534 espèces de Manche orientale et du golfe de Gascogne.

535 Main, J., Sangster, G.I., 1981. A study of the fish capture process in a bottom trawl by direct 536 observations from a towed underwater vehicle. Scott. Fish. Rep. 23.

537 Marriott, A.L., Latchford, J.W., McCarthy, I.D., 2010. Population biology of the red gurnard 538 (Aspitrigla cuculus L.; Triglidae) in the inshore waters of Eastern Anglesey and Northwest 539 Wales. J. Appl. Ichthyol. 26, 504-512.

540 Michel, S., Vandermeirsch, F., Lorance, P., 2009. Evolution of upper layer temperature in the 541 Bay of Biscay during the last 40 years. Aquat. Living Resour. 22, 447-461.

542 Myers, R.A., Worm, B., 2003. Rapid worldwide depletion of predatory fish communities. $543 \quad$ Nature 423, 280-283. 
544 Pauly, D., 1978. A preliminary compilation of fish length growth parameters. Berichte Inst.

545 Für Meereskd. Univ. Kiel 1-204.

546 Pauly, D., 1995. Anecdotes and the shifting baseline syndrome of fisheries. Trends Ecol.

547 Evol. 10, 430.

548 Quéro, J.-C., Cendrero, O., 1996. Incidence de la pêche sur la biodiversité ichtyologique

549 marine : le bassin d'Arcachon et le plateau continental Sud Gascogne. Cybium 20, 323-356.

550 Quéro, J.-C., Vayne, J.J., 1997. Les poissons de mer des pêches françaises, Ifremer. ed.

551 Delachaux \& Niestlé.

552 Report of the Working Group on the Assessment of Southern Shelf Stocks of Hake, Monk 553 and Megrim (WGHMM), 2008. . ICES, ICES Headquarters, Copenhagen.

554 Rochet, M.-J., Daurès, F., Trenkel, V.M., 2012. Capacity management, not stock status or 555 economics, drives fleet dynamics in the Bay of Biscay ecosystem on a decadal time scale.

556 Can. J. Fish. Aquat. Sci. 69, 695-710.

557 Rochet, M.-J., Trenkel, V.M., 2003. Which community indicators can measure the impact of 558 fishing? A review and proposals. Can. J. Fish. Aquat. Sci. 60, 86-99.

559 Rochet, M.-J., Trenkel, V.M., Bellail, R., Coppin, F., Le Pape, O., Mahé, J.-C., Morin, J., 560 Poulard, J.-C., Schlaich, I., Souplet, A., Vérin, Y., Bertrand, J.A., 2005. Combining indicator 561 trends to assess ongoing changes in exploited fish communities: diagnostic of communities 562 off the coasts of France. Ices J. Mar. Sci. 62, 1647-1664.

563 Rochet, M.-J., Trenkel, V.M., Carpentier, A., Coppin, F., De Sola, L.G., Léauté, J.-P., Mahé, 564 J.-C., Maiorano, P., Mannini, A., Murenu, M., Piet, G.J., Politou, C.-Y., Reale, B., Spedicato, 
565 M.-T., Tserpes, G., Bertrand, J.A., 2010. Do changes in environmental pressures impact

566 marine communities? An empirical assessment. J. Appl. Ecol. 47, 741-750.

567 Rodriguez-Cabello, C., Sanchez, F., Velasco, F., 2005. Growth of Lesser Spotted Dogfish

568 (Scyliorhinus canicula L., 1758) in the Cantabrian Sea, Based on Tag-recapture Data. J.

569 Northwest Atl. Fish. Sci. 35, 131-140.

570 Rogers, S.I., Ellis, J.R., 2000. Changes in the demersal fish assemblages of British coastal 571 waters during the 20th century. Ices J. Mar. Sci. 57, 866-881.

572 Shin, Y.-J., Rochet, M.-J., Jennings, S., Field, J.G., Gislason, H., 2005. Using size-based 573 indicators to evaluate the ecosystem effects of fishing. Ices J. Mar. Sci. 62, 384-396.

574 Winberg, G.G., 1956. Rate metabolism and food requirements of fishes. Nauch Tr. Belorussk 575 Gos Univ V Lenina Minsk 1-253.

576 Woillez, M., Poulard, J.-C., Rivoirard, J., Petitgas, P., Bez, N., 2007. Indices for capturing 577 spatial patterns and their evolution in time, with application to European hake (Merluccius 578 merluccius) in the Bay of Biscay. Ices J. Mar. Sci. 64, 537-550.

579 Xavier, J.C., Cherel, Y., Assis, C.A., Sendão, J., Borges, T.C., 2010. Feeding ecology of 580 conger eels (Conger conger) in north-east Atlantic waters. J. Mar. Biol. Assoc. United Kingd. $58190,493-501$.

582 


\section{Figure captions}

585 Fig. 1 : Map of the EVHOE survey conducted in the Bay of Biscay for the period 1987-2009.

586 Fig. 2: Relative difference in species mean weights (\%) between survey-derived and 587 simulated estimates for different values of fishing mortality F. The dotted line represents the 588 case where simulated estimates were most similar to the contemporary estimates from the 589 survey.

590 Fig. 3 : Relative difference in species mean weights (\%) between survey-derived estimates 591 (EVHOE) and estimates for populations simulated with no fishing ( $\mathrm{F}=0$, grey bars), and 592 between simulated populations with fishing at $F=M$ and estimates with no fishing (white 593 bars). The whiskers represent uncertainty intervals that include survey and parameter 594 uncertainty (see text). The black filled circle characterises the relative difference of mean 595 weight for hake with a dome-shaped selectivity curve (see text).

Fig. 4 : Length-frequency distributions above the cut off length of survey selectivity $\left(L_{\mathrm{s}}\right.$ in table 2) for contemporary survey data (dark grey) and populations simulated with no fishing (light grey). The species are ordered as in Fig. 2.

600

601 Fig. 5 : Relative difference in species mean weight (\%) between contemporary survey data 602 and values simulated without fishing mortality as a function of explanatory variables. Linear 603 quantile regression (25th percentile) for the continuous variables and boxplots (outliers not 604 drawn) for categorical variables. 
1 Tables

2 Table 1 : Number of individuals caught and length range in the EVHOE survey $(1987: 2002)$

3 (species are ordered as in Fig. 2). $L_{\mathrm{s}}$ is the cut off length, i.e. individuals $<L_{\mathrm{s}}$ were removed

4 from mean weight calculations. NA: no data.

\begin{tabular}{|c|c|c|c|}
\hline & \begin{tabular}{|c|} 
Number of \\
individual caught
\end{tabular} & $\begin{array}{l}\text { Length range } \\
\text { (cm) }\end{array}$ & $L_{\mathrm{s}}(\mathrm{cm})$ \\
\hline \multicolumn{4}{|l|}{ Species } \\
\hline Conger conger & 1390 & $27-210$ & 40 \\
\hline Merluccius merluccius & 254045 & $3-108$ & 9 \\
\hline Lophius piscatorius & 1935 & $6-124$ & 13 \\
\hline \multicolumn{4}{|l|}{ Chelidonichthys } \\
\hline cuculus & 9010 & $1-45$ & 15 \\
\hline Phycis blennoides & 3567 & $6-66$ & 12 \\
\hline Trachurus trachurus & 7602332 & $3-56$ & 8 \\
\hline Mullus surmuletus & 9322 & $3-45$ & 9 \\
\hline Callionymus lyra & 14955 & $4-32$ & 12 \\
\hline Solea solea & 1405 & $6-52$ & 17 \\
\hline Lophius budegassa & 1047 & $5-91$ & 7 \\
\hline \multicolumn{4}{|l|}{ Chelidonichthys } \\
\hline gurnardus & 1519 & $5-49$ & 15 \\
\hline Zeus faber & 1624 & $3-58$ & 15 \\
\hline Trisopterus luscus & 181545 & $5-46$ & 8 \\
\hline Dicentrarchus labrax & 956 & $27-87$ & 30 \\
\hline Merlangius merlangus & 34058 & $4-55$ & 9 \\
\hline
\end{tabular}




\begin{tabular}{|l|c|c|c|} 
Lepidorhombus & & & \\
whiffiagonis & 5503 & $3-56$ & 15 \\
\hline Scyliorhinus canicula & 22883 & $9-82$ & 26 \\
\hline Dicologlossa cuneata & 1409 & $6-29$ & 14 \\
\hline Total / Range & $\mathbf{8 1 4 8 5 0 5}$ & $\mathbf{1 - 2 1 0}$ & $\mathbf{7 - 4 0}$ \\
\hline
\end{tabular}

5

6

7

8

9

10

11

12

13

14

15 
Table 2 : Life-history trait estimates used for simulating population structure at equilibrium A median $L_{\text {inf }}$ value was used when more than one value was available (species are ordered as in Figure 2). $K$ and $L_{\text {inf }}$ : von Bertalanfy growth and asymptotic length; Lmat length-at-maturity; $\alpha$ and $\beta$ parameters of length-weight relationship $W=\alpha L^{\beta} ; M$ natural mortality.

\begin{tabular}{|l|l|l|l|l|l|l|l|}
\hline Species & $\boldsymbol{K}$ & $\boldsymbol{L}_{\text {inf }}$ & $\boldsymbol{L}$ mat & $\boldsymbol{\alpha}[4]$ & $\boldsymbol{\beta}[4]$ & $\boldsymbol{M}_{\text {study }}$ & $\boldsymbol{M}_{\text {Ander }}$ \\
\hline Conger conger & $0.0680[4]$ & $265[13]$ & $200[11]$ & 0.00023 & 3.4991 & 0.098 & 0.03 \\
\hline Merluccius merluccius & $0.181[4]$ & $106[4][10]$ & $48.5[3]$ & 0.00438 & 3.1130 & 0.31 & 0.11 \\
\hline Lophius piscatorius & $0.0882[4]$ & $134.5[4][10][3]$ & $65[4]$ & 0.02457 & 2.85612 & 0.15 & 0.05 \\
\hline Chelidonichthys & & & & & & & \\
cuculus & $0.46[2]$ & $46[4][10][3]$ & $25[11]$ & 0.00325 & 3.31963 & 0.74 & 0.25 \\
\hline Phycis blennoides & $0.217[6]$ & $69.25[4][10]$ & $33[11]$ & 0.213006 & 2.103422 & 0.36 & 0.13 \\
\hline Trachurus trachurus & $0.2[8]$ & $50[4][10][3]$ & $24.5[3]$ & 0.00733 & 3.02544 & 0.33 & 0.11 \\
\hline Mullus surmuletus & $0.3[2]$ & $44.5[4][10][3]$ & $17[3]$ & 0.00512 & 3.29558 & 0.54 & 0.19 \\
\hline Callionymus lyra & $0.47[1]$ & $40[10]$ & $13[1]$ & 0.014 & 2.70900 & 0.89 & 0.31 \\
\hline Solea solea & $0.278[4]$ & $58.5[4][10][3]$ & $25.5[4]$ & 0.00475 & 3.18094 & 0.48 & 0.16 \\
\hline Lophius budegassa & $0.1102[4]$ & $88[4][10]$ & $58.5[4]$ & 0.015 & 3.00400 & 0.16 & 0.06 \\
\hline Chelidonichthys & & & & & & & \\
\hline gurnardus & $0.48[12]$ & $44.5[4][10][3]$ & $21[4]$ & 0.00671 & 3.06235 & 0.80 & 0.28 \\
\hline Zeus faber & $0.2085[9]$ & $58[4][10][3]$ & $37[3]$ & 0.01809 & 2.98270 & 0.31 & 0.11 \\
\hline Trisopterus luscus & $0.47[4]$ & $44.5[4][10][3]$ & $20[4]$ & 0.00738 & 3.15608 & 0.8 & 0.28 \\
\hline Dicentrarchus labrax & $0.13[4]$ & $85[4][10]$ & $37[4]$ & 0.01248 & 2.94846 & 0.22 & 0.08 \\
\hline Merlangius merlangus & $0.238[4]$ & $55[4][10][3]$ & $21[4]$ & 0.00455 & 3.16690 & 0.43 & 0.15 \\
\hline Lepidorhombus & $0.104[4]$ & $57.5[4][10]$ & $22.5[4]$ & 0.00307 & 3.24460 & 0.19 & 0.06 \\
\hline
\end{tabular}




\begin{tabular}{|l|l|l|l|l|l|l|l|} 
Scyliorhinus canicula & $0.21[7]$ & $74[4][10][3]$ & $57[4]$ & 0.00342 & 2.99468 & 0.3 & 0.3 \\
\hline Dicologlossa cuneata & $0.47[5]$ & $27.75[10][3]$ & $15[4]$ & 0.0066 & 3.00000 & 0.75 & 0.75 \\
\hline
\end{tabular}

20 [1] Jennings et al., 1999; [2] Mahé et al., 2006; [3] Dorel, 1986; [4] Dorel et al., 1998; [5]

21 Félix et al., 2011; [6] Casas and Piñeiro, 2000; [7] Rodriguez-Cabello et al., 2005; [8]

22 Cubillos and Arancibia, 1995; [9] Pauly, 1978; [10] Maximum lenght from EVHOE surveys;

23 [11] http://www.fishbase.org; [12] Magnussen, 2007; [13] Correia et al., 2009. 
Table 3 : Categorical variables used to investigate the relationship between management measures, habitat or life history traits and relative differences in mean weight between populations at equilibrium or under fishing pressure (species are ordered as in Fig. 2). Depth category : Coastal $=0 \mathrm{~m}-100 \mathrm{~m}$; Shelf $=100 \mathrm{~m}-450 \mathrm{~m} ;$ Slope $=>450 \mathrm{~m}$.

\begin{tabular}{|l|l|l|l|l|l|}
\hline Species & TAC & & Landings & Latitudinal & Depth \\
[1] & Shape & [2] & distribution [3] & category[4] \\
\hline Conger conger & No & Round & Low & Subtropical & Shelf \\
\hline Merluccius merluccius & Yes & Round & High & Temperate & Slope \\
\hline Lophius piscatorius & Yes & Flat & High & Temperate & Slope \\
\hline Chelidonichthys cuculus & No & Round & Low & Subtropical & Shelf \\
\hline Phycis blennoides & No & Round & Low & Boreal & Slope \\
\hline Trachurus trachurus & Yes & Round & Medium & Subtropical & Slope \\
\hline Mullus surmuletus & No & Round & Medium & Subtropical & Shelf \\
\hline Callionymus lyra & No & Round & Low & Temperate & Shelf \\
\hline Solea solea & Yes & Flat & High & Subtropical & Coastal \\
\hline Lophius budegassa & Yes & Flat & High & Subtropical & Slope \\
\hline Chelidonichthys & & & & & Temperate \\
\hline gurnardus & No & Round & Low & Shelf \\
\hline Zeus faber & No & Round & Medium & Subtropical & Slope \\
\hline Trisopterus luscus & No & Round & Low & Temperate & Shelf \\
\hline Dicentrarchus labrax & Yes & Round & High & Subtropical & Coastal \\
\hline Merlangius merlangus & Yes & Round & Medium & Boreal & Shelf \\
\hline Lepidorhombus & & & & & Slope \\
\hline
\end{tabular}




\begin{tabular}{|l|l|l|l|l|l|} 
Scyliorhinus canicula & No & Round & Low & Subtropical & Coastal \\
\hline Dicologlossa cuneata & No & Flat & Low & Subtropical & Coastal \\
\hline
\end{tabular}

37 [1] European commission : http://ec.europa.eu/fisheries/cfp/fishing_rules/tacs/index_en.htm;

38 [2] French landings for the year 2009; [3] Blanchard et al., 2001; [4] Quéro and Vayne, 1997. 


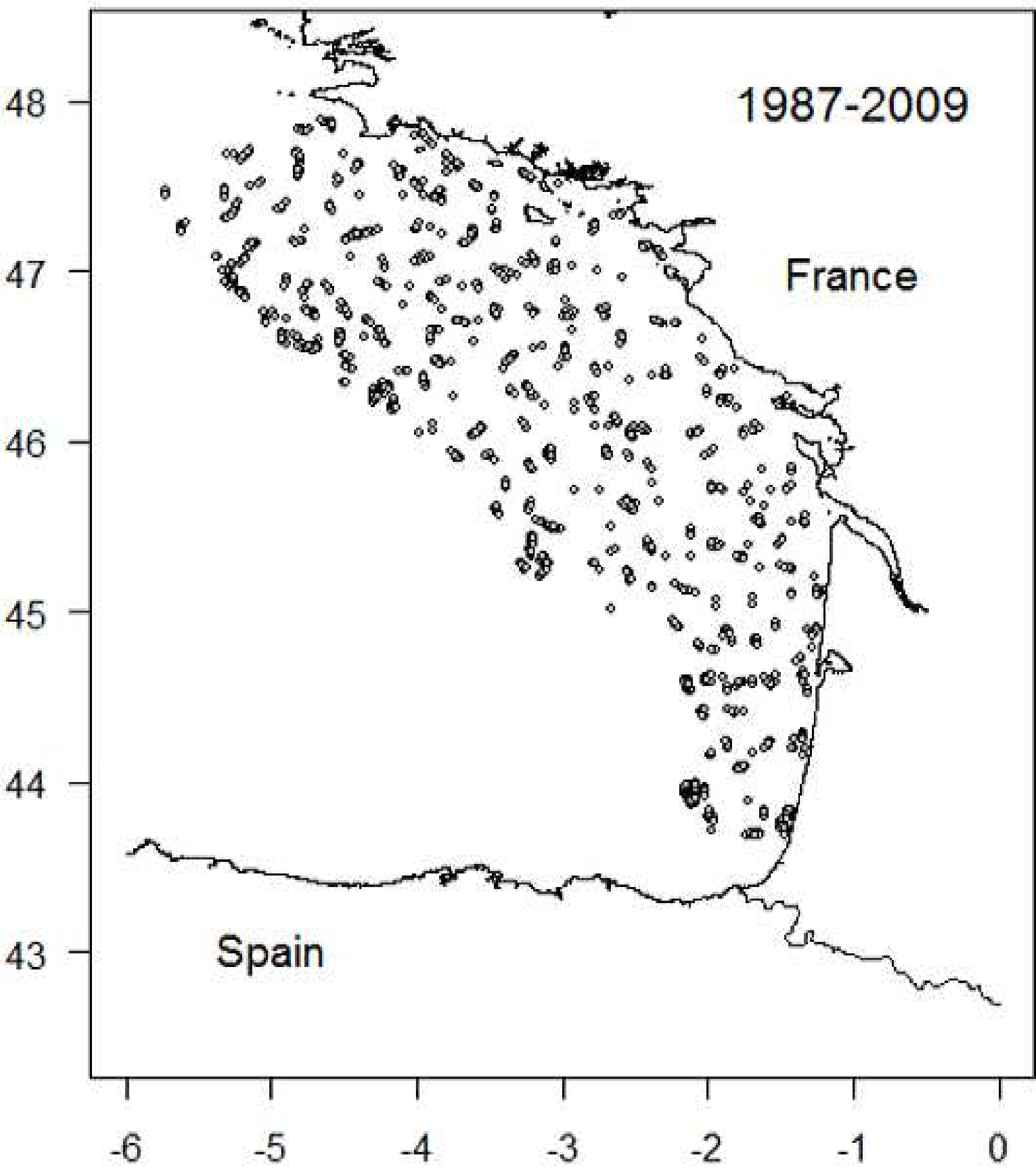


Callionymus lyra

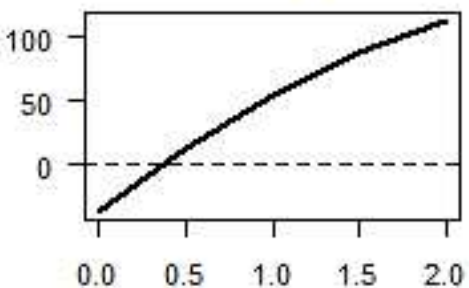

Conger conger

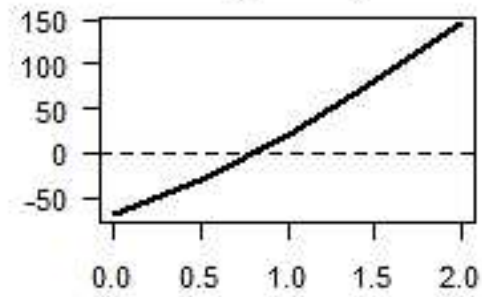

Lepidorhombus whiffiagonis

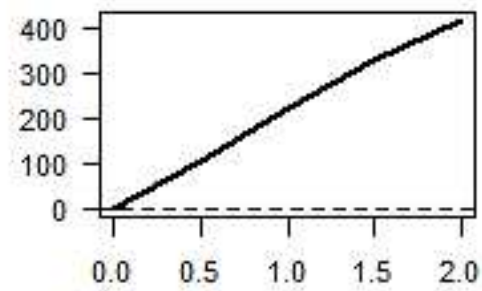

Merlangius merlangus

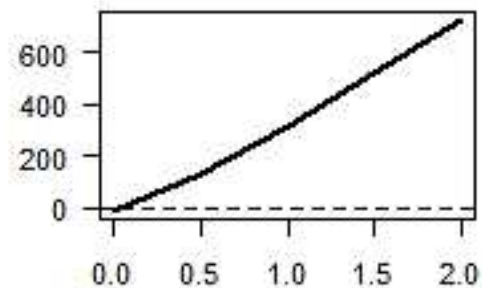

Phycis blennoides

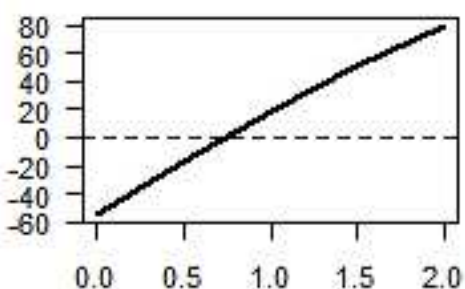

Trachurus trachurus

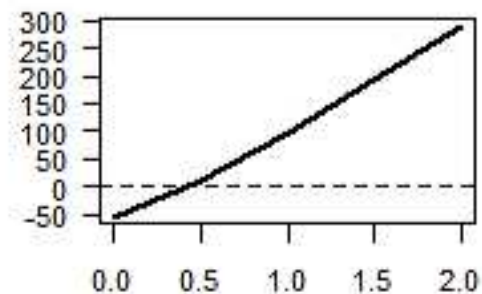

Chelidonichthys cuculus
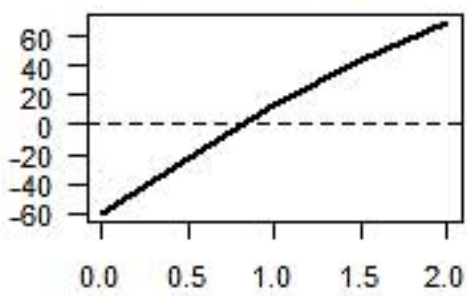

Dicentrarchus labrax

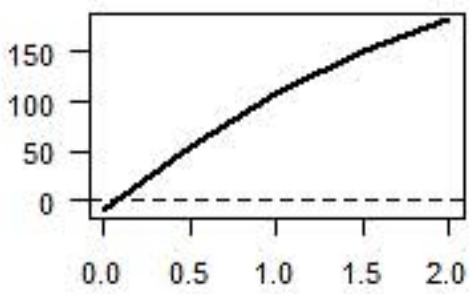

Lophius budegassa

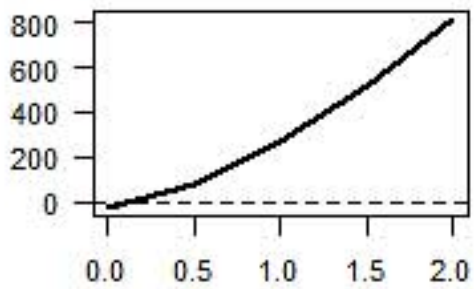

Merluccius merluccius

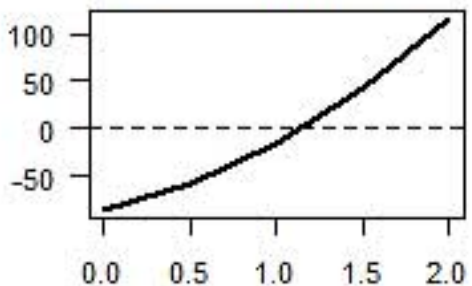

Scyliorhinus canicula

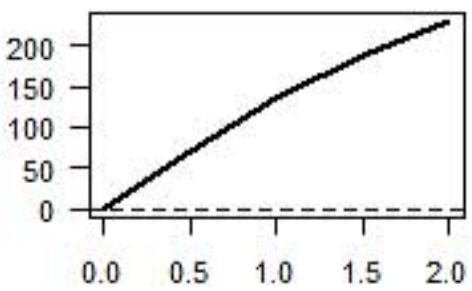

Trisopterus luscus

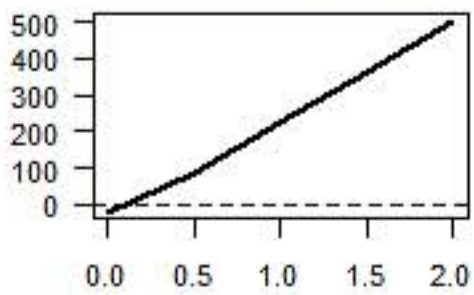

Chelidonichthys gurnardus

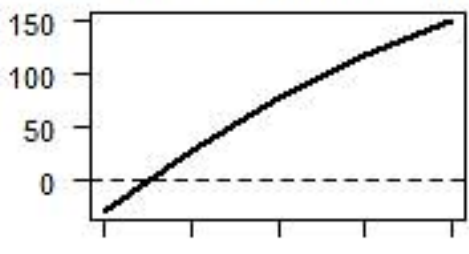

$\begin{array}{lllll}0.0 & 0.5 & 1.0 & 1.5 & 2.0\end{array}$

Dicologlossa cuneata

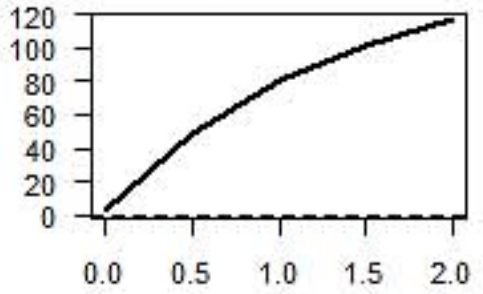

Lophius piscatorius

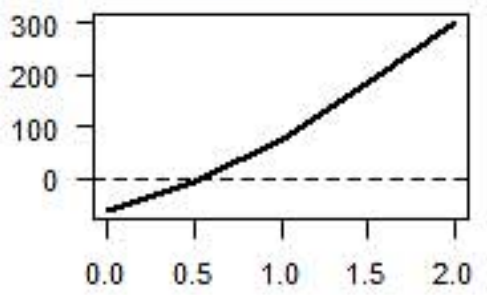

Mullus surmuletus

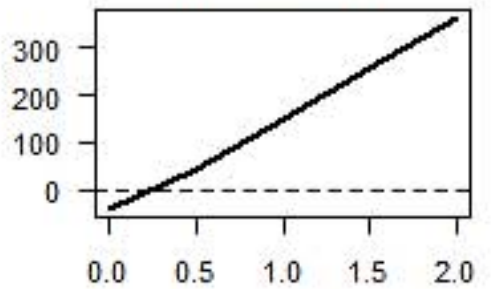

Solea solea

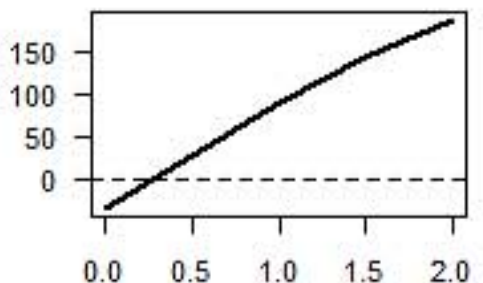

Zeus faber

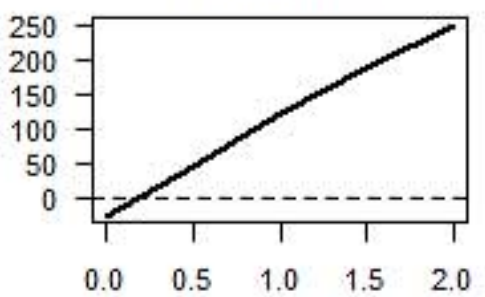


Conger conger

Merluccius merluccius

Lophius piscatorius

Chelidonichthys cuculus

Phycis blennoides

Trachurus trachurus

Mullus surmuletus

Callionymus lyra

Solea solea

Lophius budegassa

Chelidonichthys gurnardus

Zeus faber

Trisopterus luscus

Dicentrarchus labrax

Merlangius merlangus Lepidorhombus whiffiagonis

Scyliorhinus canicula

Dicologlossa cuneata
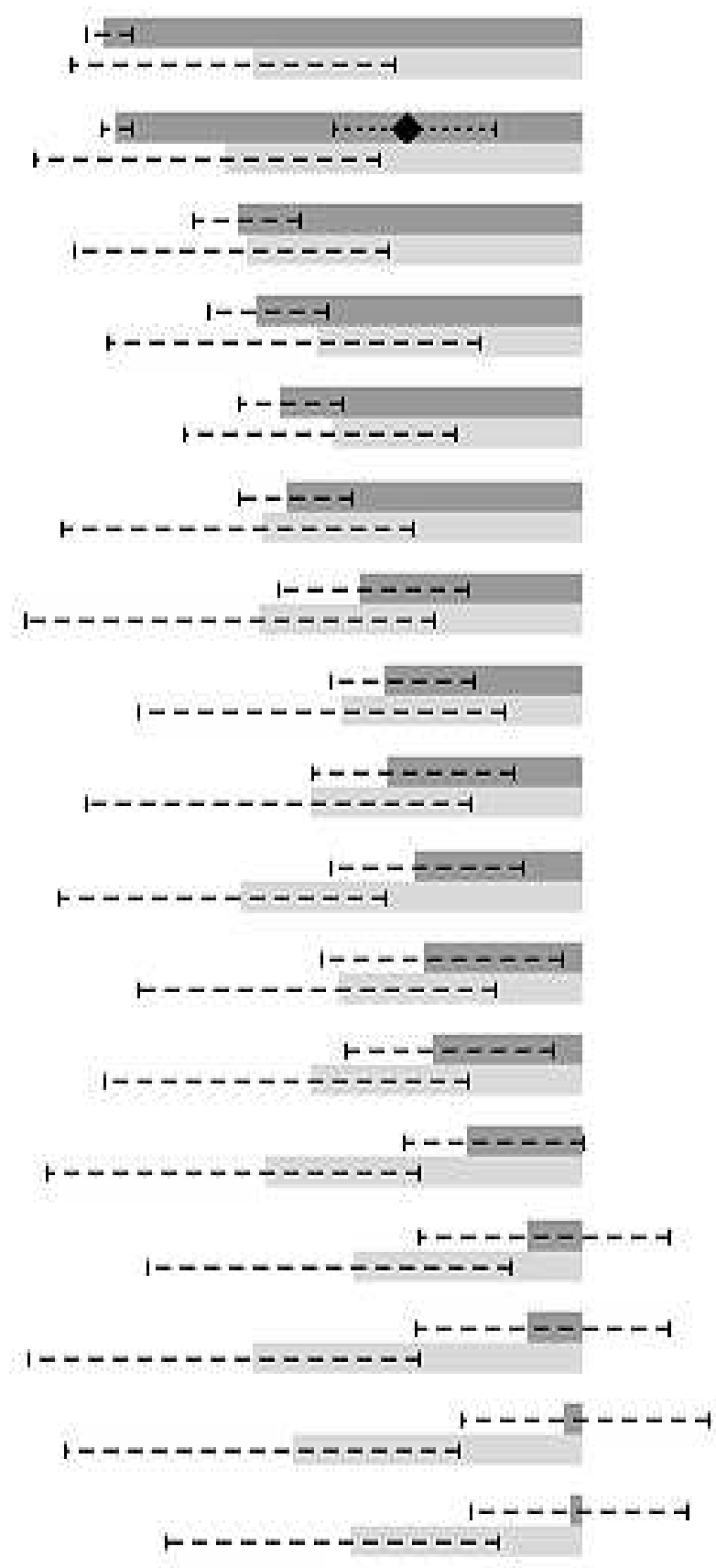

1 - - - -

\section{प| | | | | | | | | | | | | | | | | | | \\ $\begin{array}{llllll}-110 & -80 & -50 & -20 & 10 & 40\end{array}$}

Relative difference (\%) 

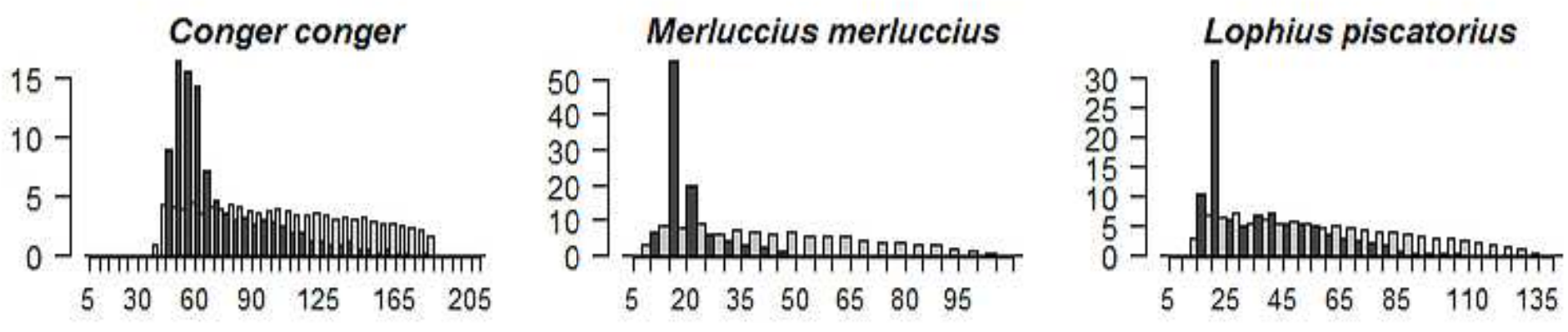

Chelidonichthys cuculus

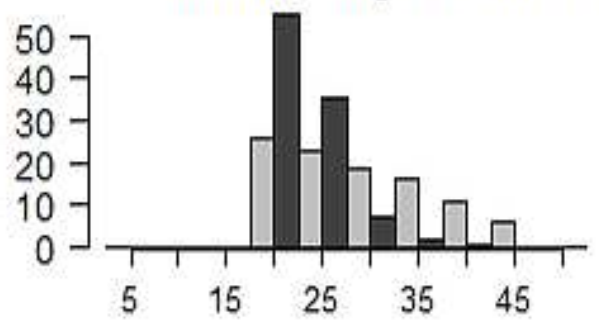

Phycis blennoides

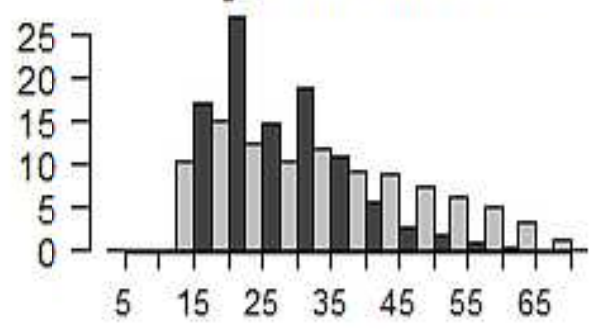

Trachurus trachurus

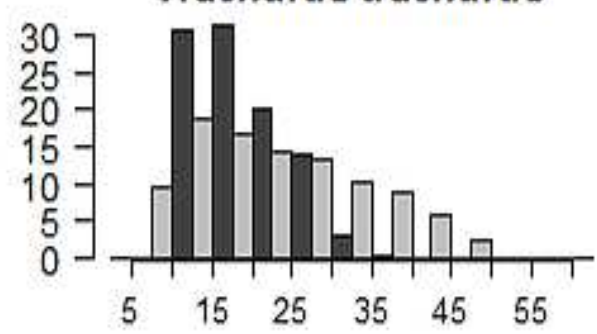

Mullus surmuletus

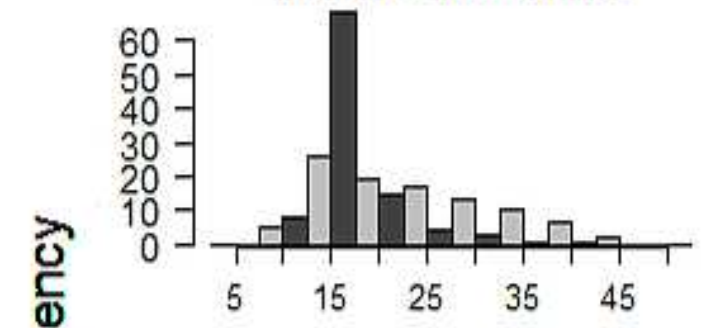

Lophius budegassa

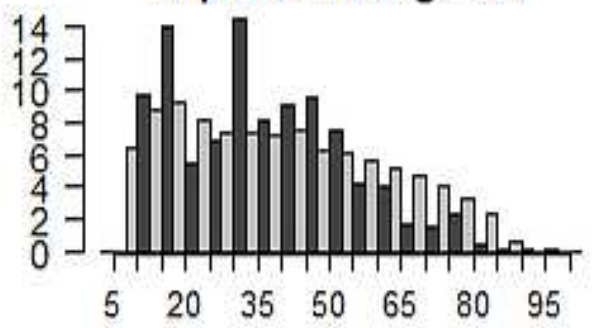

Trisopterus luscus
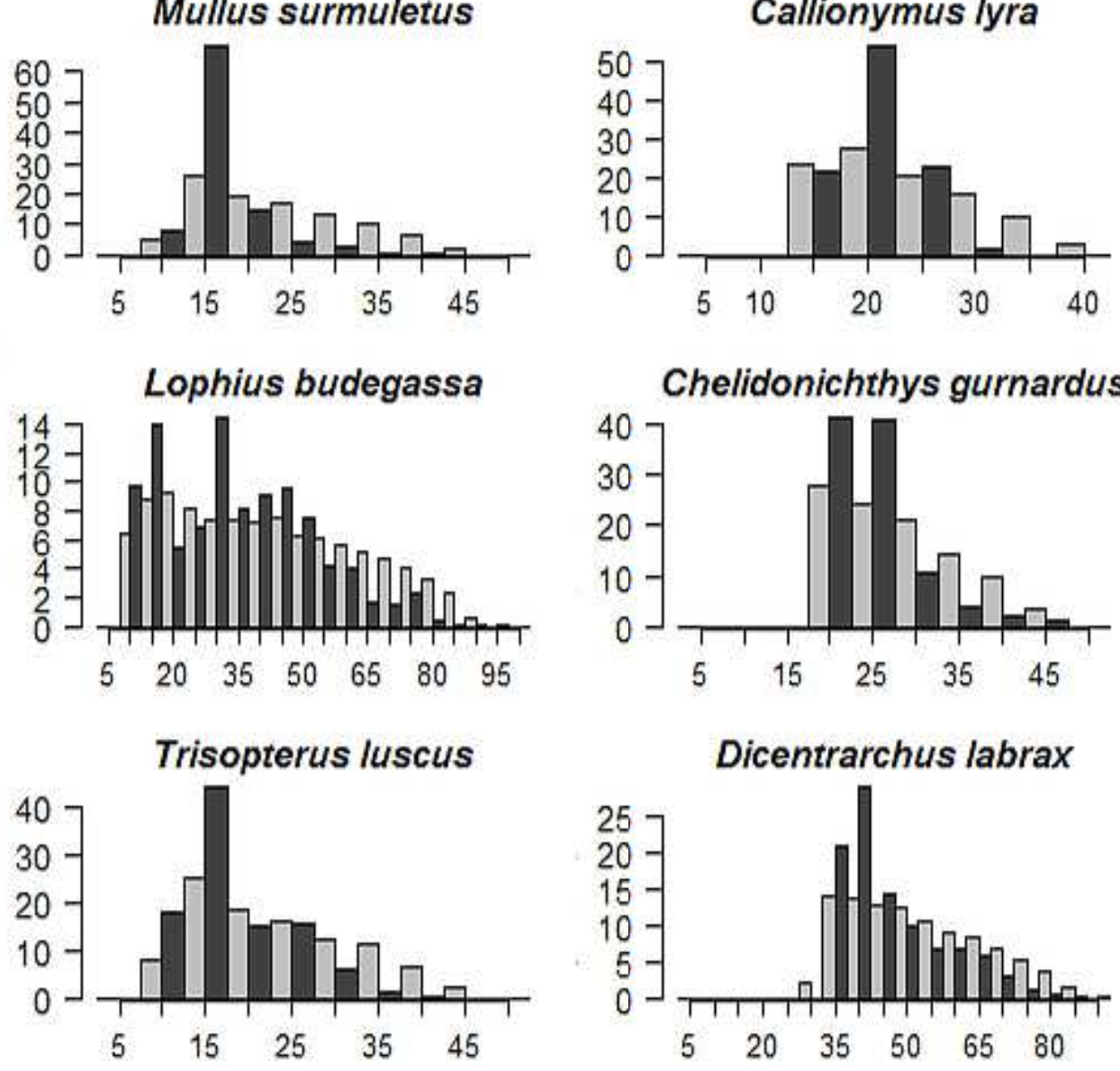

Solea solea
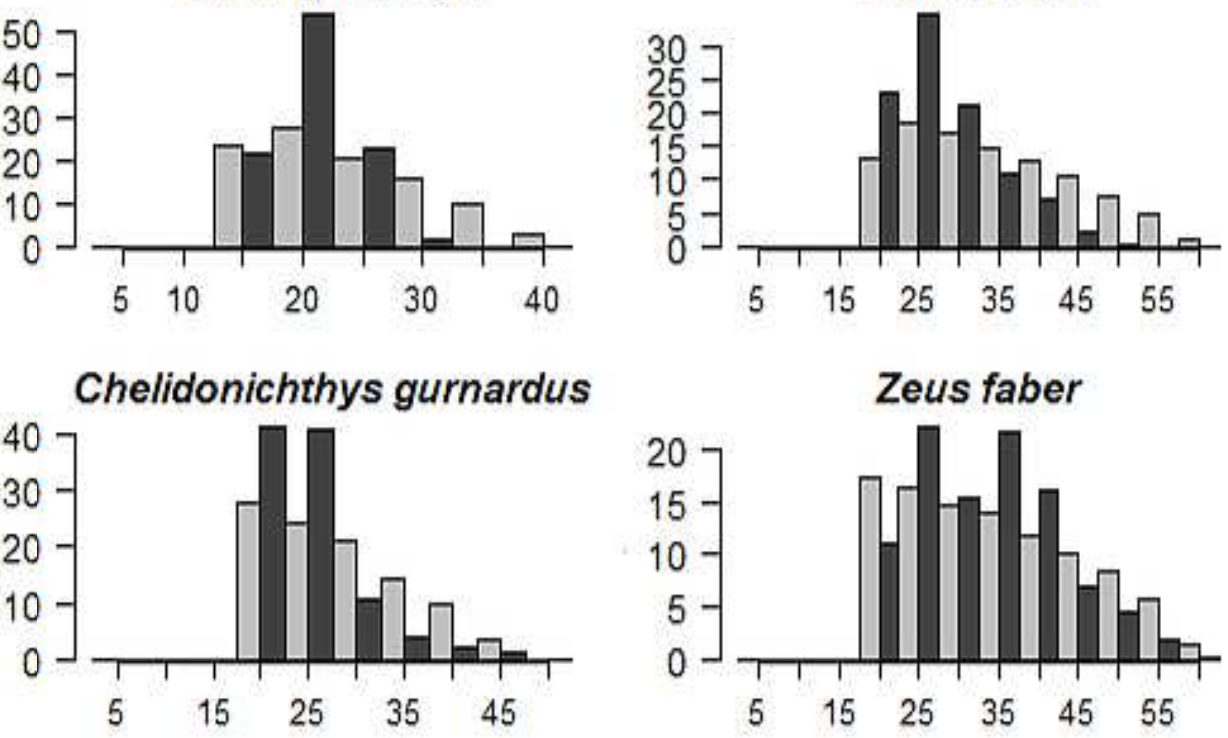

Dicentrarchus labrax

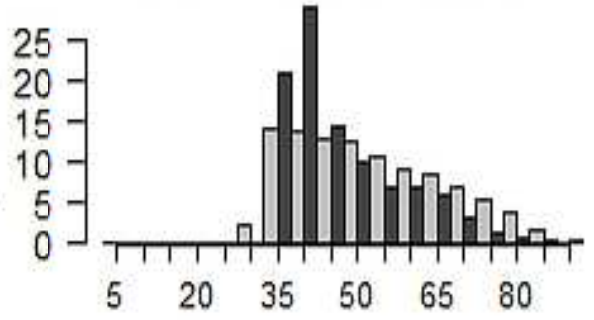

Merlangius merlangus

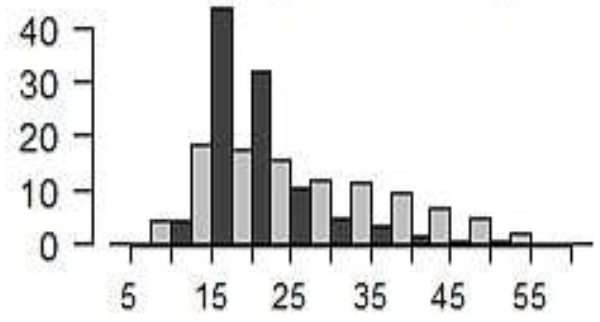

Lepidorhombus whiffiagonis

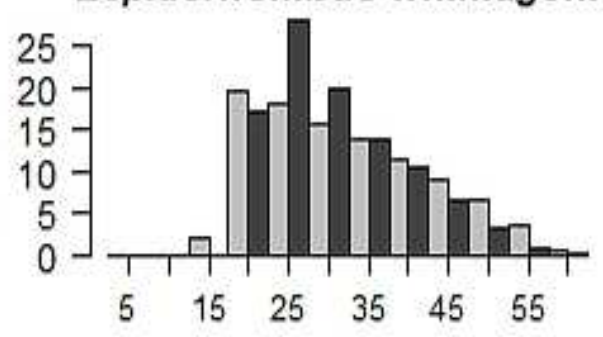

Scyliorhinus canicula

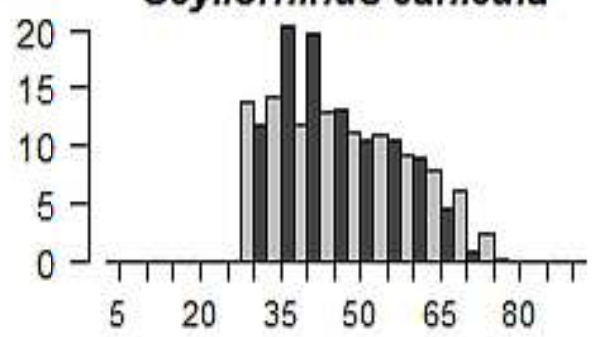

Dicologlossa cuneata

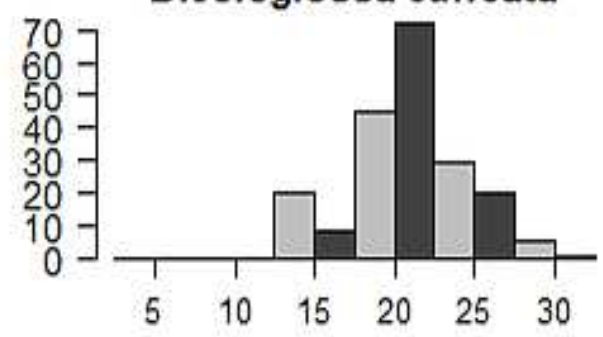

Size $(\mathrm{cm})$ 
slope $=76.7532$

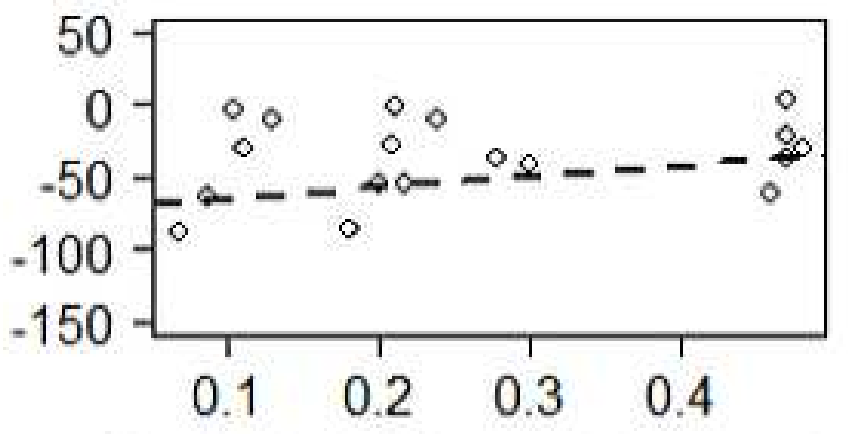

Von bertalanffy's growth parameter

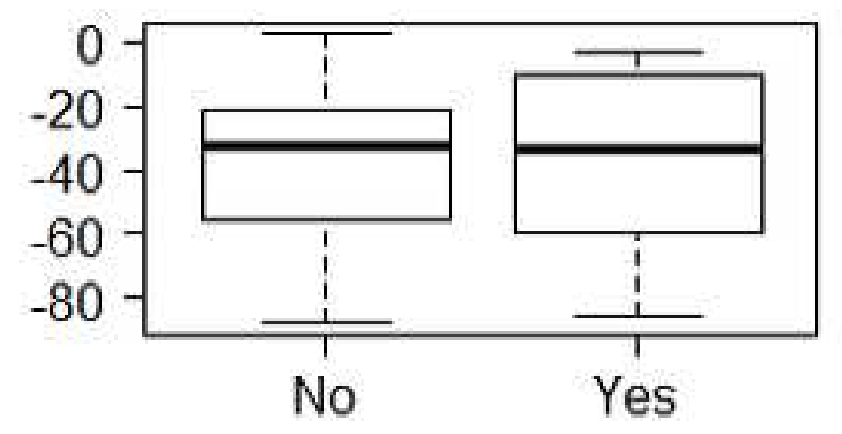

TAC

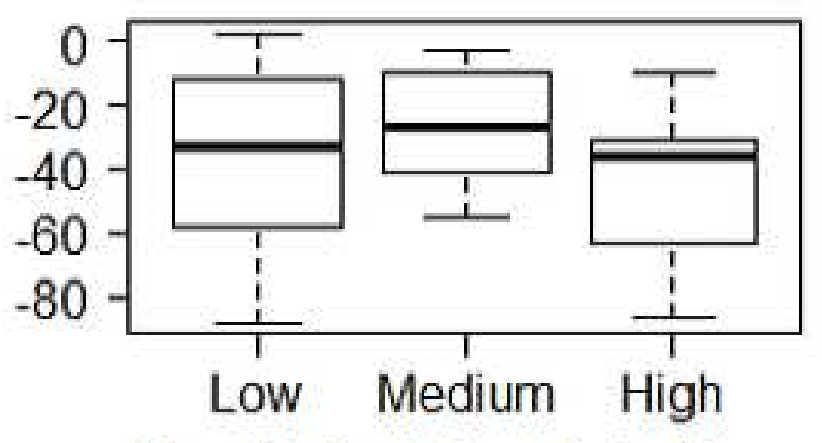

Magnitude of French landings

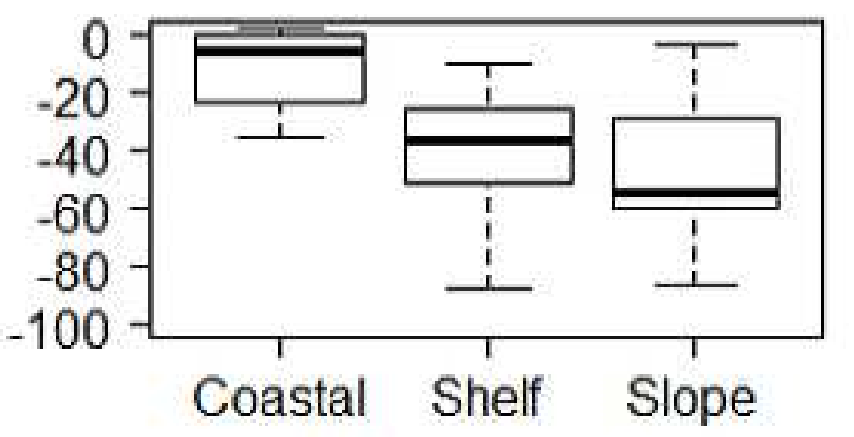

Maximum depth slope $=-0.2498$

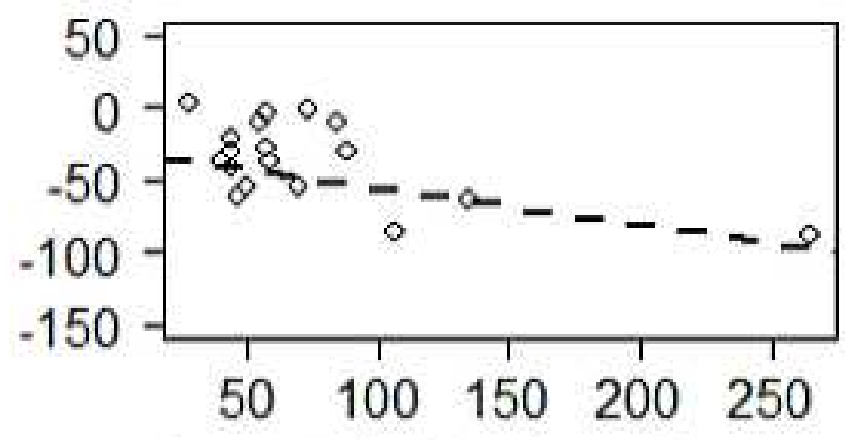
Asymptotic size in centimeters

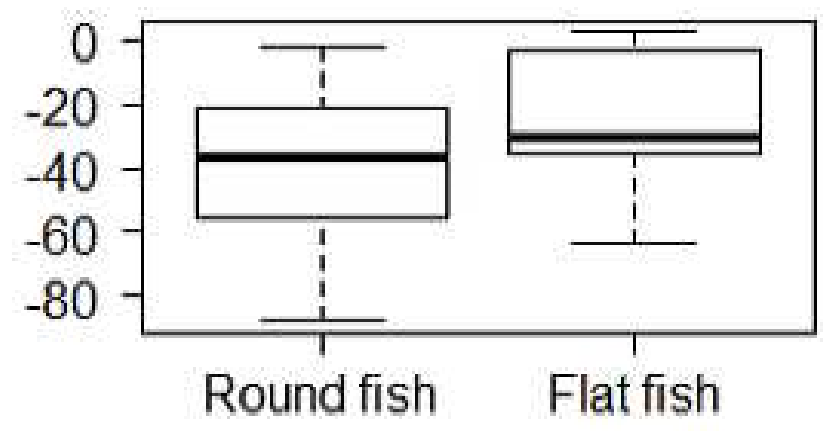

Body shape

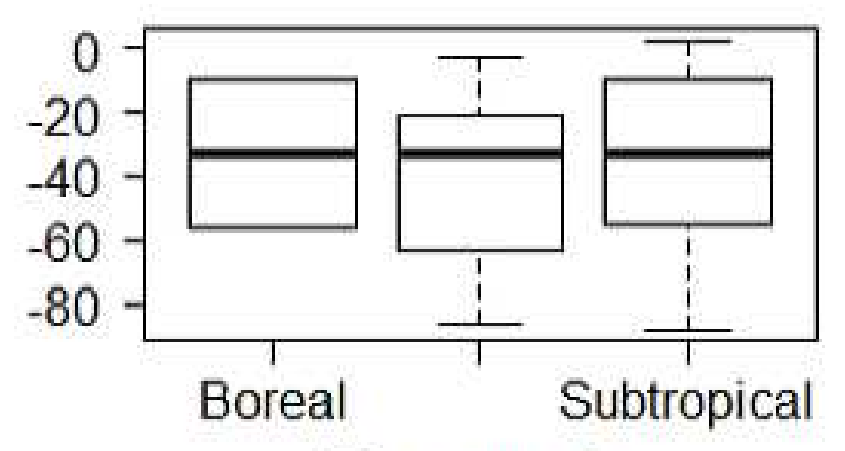

Biogeography 
Corrigendum to: Evaluating the potential impact of fishing on demersal species in the Bay of Biscay using simulations and survey data

An error was detected in the calculation of natural mortality values using the model by Andersen et al. in equation (1). The corrected $M$ values ( $\left.M_{\text {Andersen et al. }}\right)$ and those used in the study ( $\left.\mathrm{M}_{\text {study }}\right)$ are given in Table 2 . A revised version of the table is provided below:

Table 1 : Life-history trait estimates used for simulating population structure at equilibrium A median $L_{\text {inf }}$ value was used when more than one value was available (species are ordered as in Figure 2). $K$ and $L_{\text {inf }}$ : von Bertalanfy growth and asymptotic length; Lmat length-at-maturity; $\alpha$ and $\beta$ parameters of length-weight relationship $W=\alpha L^{\beta} ; M_{\text {study }}$ natural mortality used in this study; $M_{\text {Andersen at al. }}$ natural mortality estimated using Andersen's formula (i.e. equation (1) in the paper).

\begin{tabular}{|c|c|c|c|c|c|c|c|}
\hline Species & $K$ & $L_{\text {inf }}$ & Lmat & $\alpha[4]$ & $6[4]$ & $M_{\text {study }}$ & $M_{\text {Andersen et al. }}$ \\
\hline Conger conger & $0.0680[4]$ & 265 [13] & $200[11]$ & 0.00023 & 3.4991 & 0.098 & 0.03 \\
\hline Merluccius merluccius & $0.181[4]$ & $106[4][10]$ & $48.5[3]$ & 0.00438 & 3.1130 & 0.31 & 0.11 \\
\hline Lophius piscatorius & $0.0882[4]$ & 134.5 [4] [10] [3] & $65[4]$ & 0.02457 & 2.85612 & 0.15 & 0.05 \\
\hline Chelidonichthys cuculus & $0.46[2]$ & 46 [4] [10] [3] & $25[11]$ & 0.00325 & 3.31963 & 0.74 & 0.25 \\
\hline Phycis blennoides & $0.217[6]$ & 69.25 [4] [10] & $33[11]$ & 0.213006 & 2.103422 & 0.36 & 0.13 \\
\hline Trachurus trachurus & $0.2[8]$ & 50 [4] [10] [3] & $24.5[3]$ & 0.00733 & 3.02544 & 0.33 & 0.11 \\
\hline Mullus surmuletus & $0.3[2]$ & 44.5 [4] [10] [3] & $17[3]$ & 0.00512 & 3.29558 & 0.54 & 0.19 \\
\hline Callionymus lyra & $0.47[1]$ & $40[10]$ & $13[1]$ & 0.014 & 2.70900 & 0.89 & 0.31 \\
\hline Solea solea & $0.278[4]$ & 58.5 [4] [10] [3] & $25.5[4]$ & 0.00475 & 3.18094 & 0.48 & 0.16 \\
\hline Lophius budegassa & $0.1102[4]$ & 88 [4] [10] & 58.5 [4] & 0.015 & 3.00400 & 0.16 & 0.06 \\
\hline $\begin{array}{l}\text { Chelidonichthys } \\
\text { gurnardus }\end{array}$ & 0.48 [12] & 44.5 [4] [10] [3] & $21[4]$ & 0.00671 & 3.06235 & 0.80 & 0.28 \\
\hline
\end{tabular}




\begin{tabular}{|l|l|l|l|l|l|l|l|}
\hline & $0.2085[9]$ & $58[4][10][3]$ & $37[3]$ & 0.01809 & 2.98270 & 0.31 & 0.11 \\
\hline Trisopterus luscus & $0.47[4]$ & $44.5[4][10][3]$ & $20[4]$ & 0.00738 & 3.15608 & 0.8 & 0.28 \\
\hline Dicentrarchus labrax & $0.13[4]$ & $85[4][10]$ & $37[4]$ & 0.01248 & 2.94846 & 0.22 & 0.08 \\
\hline Merlangius merlangus & $0.238[4]$ & $55[4][10][3]$ & $21[4]$ & 0.00455 & 3.16690 & 0.43 & 0.15 \\
\hline Lepidorhombus & & & & & & & \\
whiffiagonis & $0.104[4]$ & $57.5[4][10]$ & $22.5[4]$ & 0.00307 & 3.24460 & 0.19 & 0.06 \\
\hline
\end{tabular}


Ravard et al.

Evaluating the potential impact of fishing on demersal species in the Bay of Biscay using simulations and survey data

\section{Electronic supplementary material}

Figure legends:

Fig. S1: Annual mean weight for nine groundfish species from EVHOE surveys (1987-2009). Solid line represents the annual mean weight by station (see text), dashed lines represent 2 standard deviations around the mean.

Fig. S2: Size structure of the firsts nine species (in alphabetical order) sampled by EVHOE surveys between 1987 and 2009, all year pooled. Solid line (i.e. $L_{s}$ ) represents the mean level of truncation that was applied for each species. All individuals below $L_{s}$ were removed before mean weight calculation. Dotted lines represent the age at size of species (i.e. 0,5 year / 1 year / 1,5 years and 2 years).

Fig. S3: Size structure of the firsts nine species (in alphabetical order) populations at equilibrium. Solid line (i.e. $L_{s}$ ) represents the mean level of truncation that was applied for each species. All individuals below $L_{s}$ were removed before mean weight calculation. Dotted lines represent the age at size of species (i.e. 0,5 year / 1 year / 1,5 years and 2 years). 

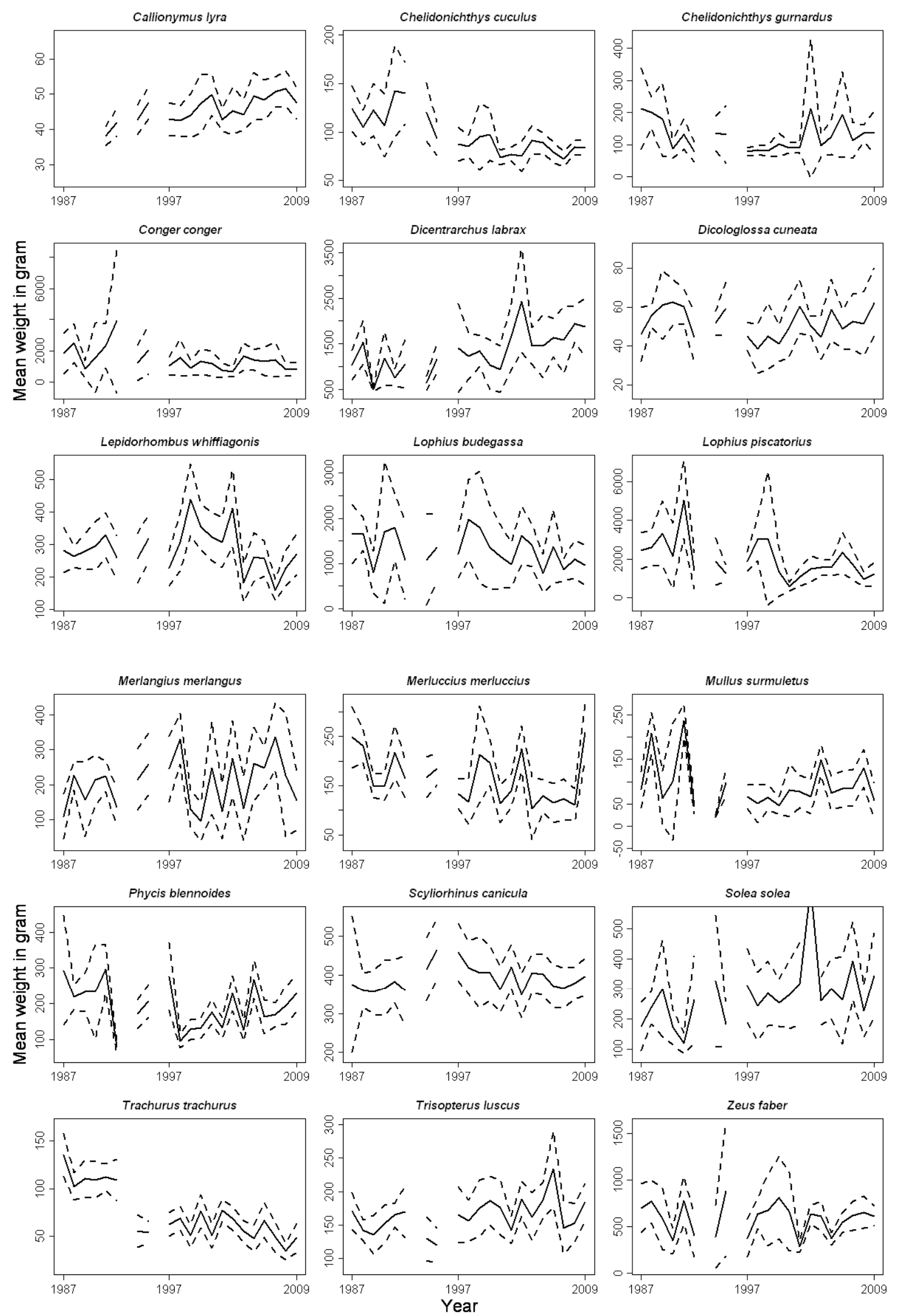
Fig. S1: Annual mean weight for nine groundfish species from EVHOE surveys (1987-2009). Solid line represents the annual mean weight by station (see text), dashed lines represent 2 standard deviations around the mean. 


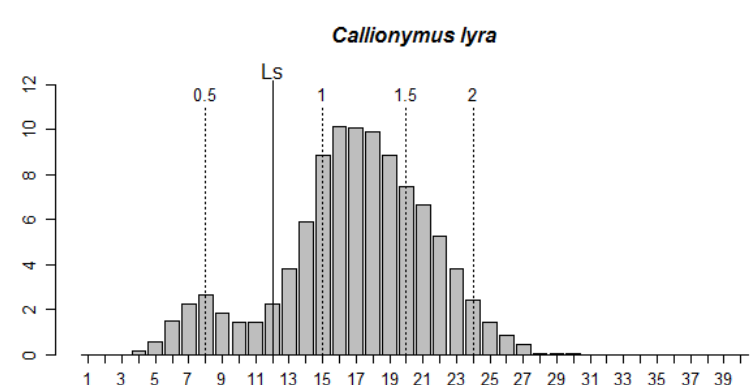

Conger conger

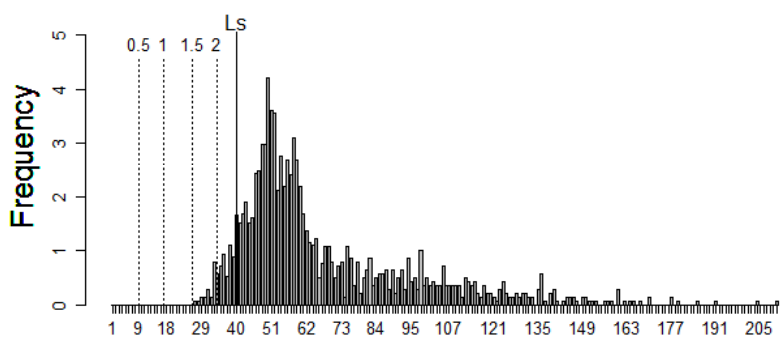

Lepidorhombus whiffiagonis

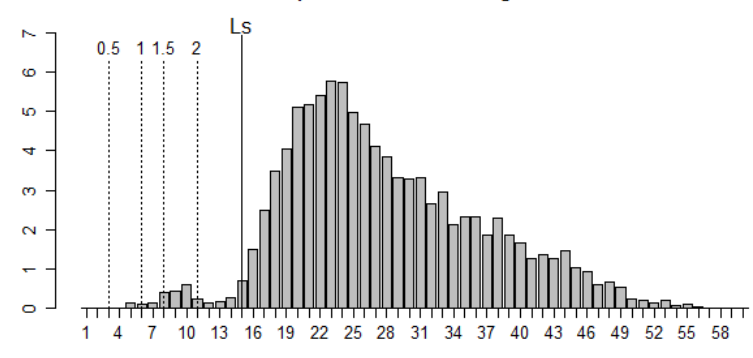

Chelidonichthys cuculus

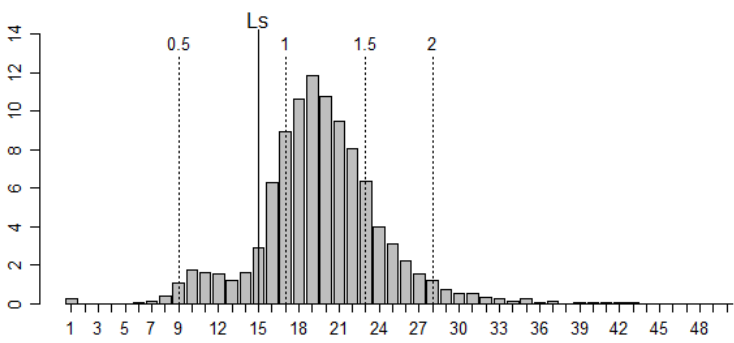

Dicentrarchus labrax

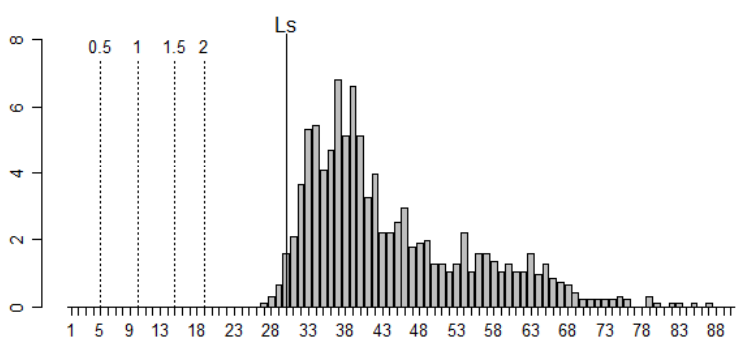

Lophius budegassa

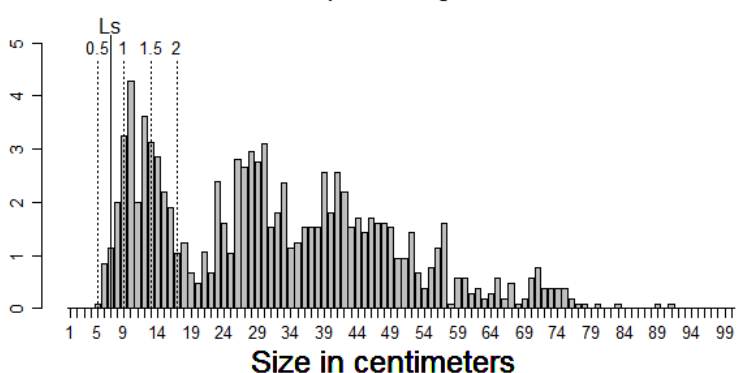

Chelidonichthys gurnardus

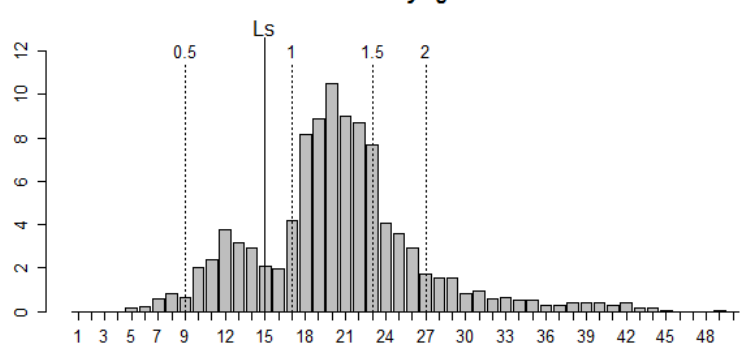

Dicologlossa cuneata

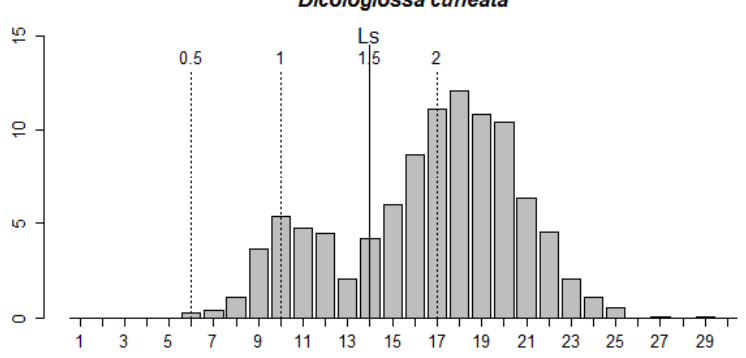

Lophius piscatorius

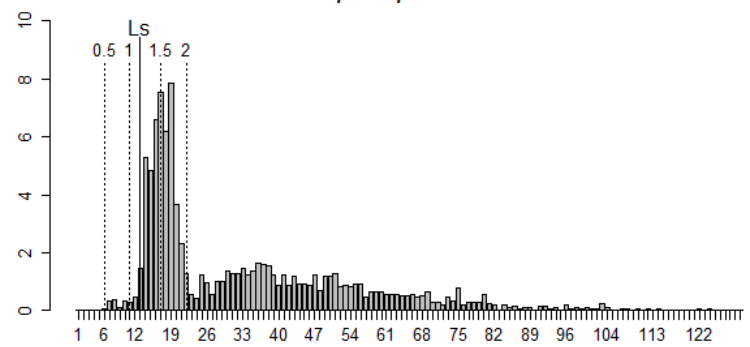

Fig. S2: Size structure of the firsts nine species (in alphabetical order) sampled by EVHOE surveys between 1987 and 2009 , all year pooled. Solid line (i.e. $L_{s}$ ) represents the mean level of truncation that was applied for each species. All individuals below $L_{\mathrm{s}}$ were removed before mean weight calculation. Dotted lines represent the age at size of species (i.e. 0,5 year / 1 year / 1,5 years and 2 years). 


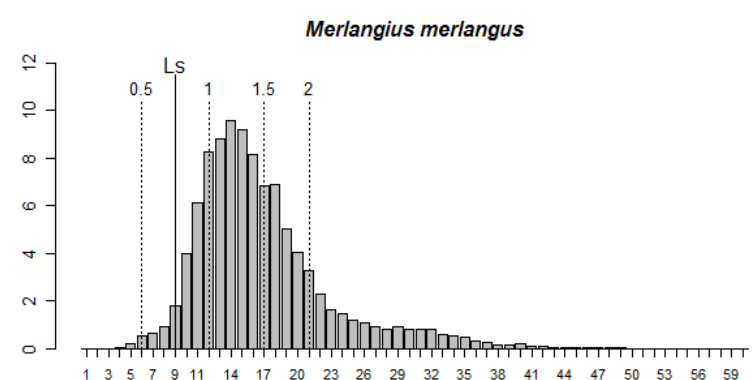

Phycis blennoides

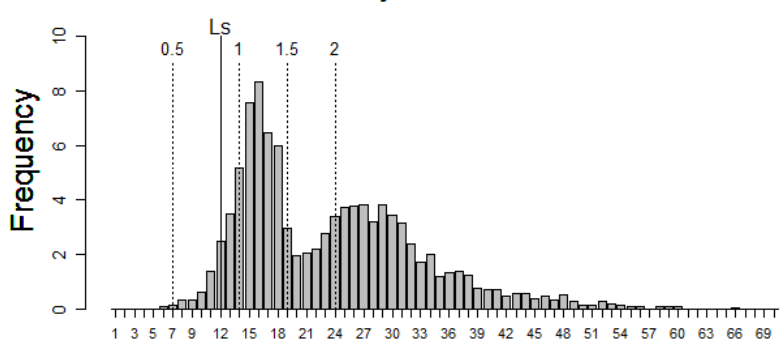

Trachurus trachurus

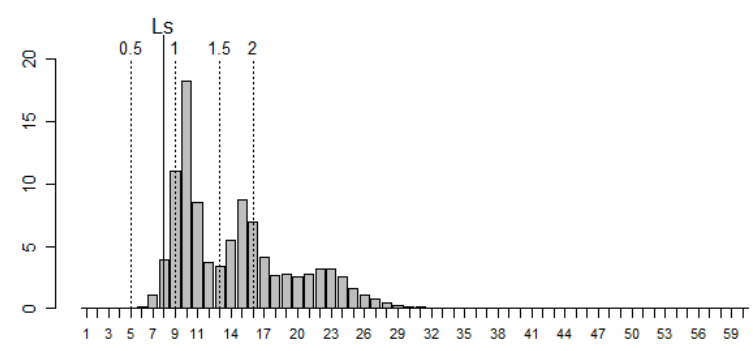

Merluccius merluccius

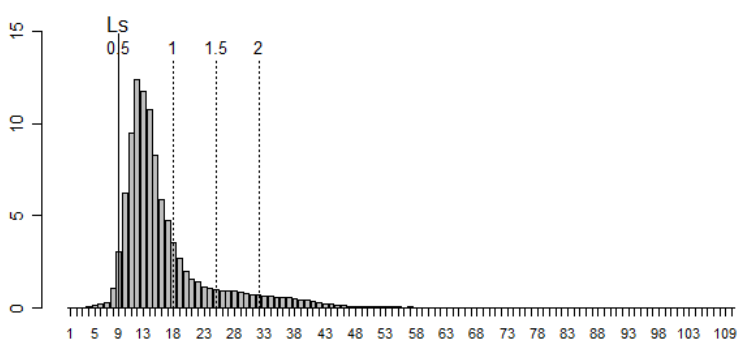

Scyliorhinus canicula

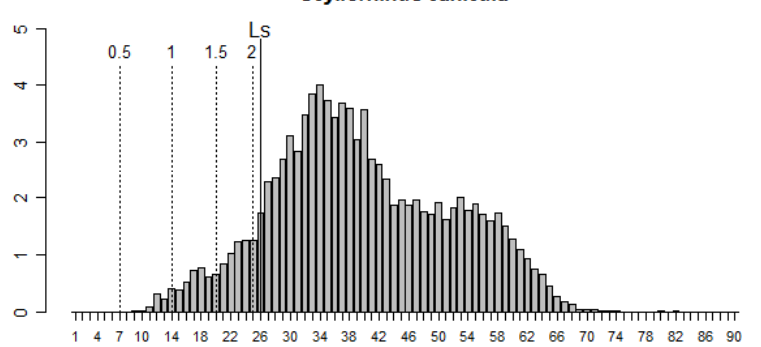

Trisopterus luscus

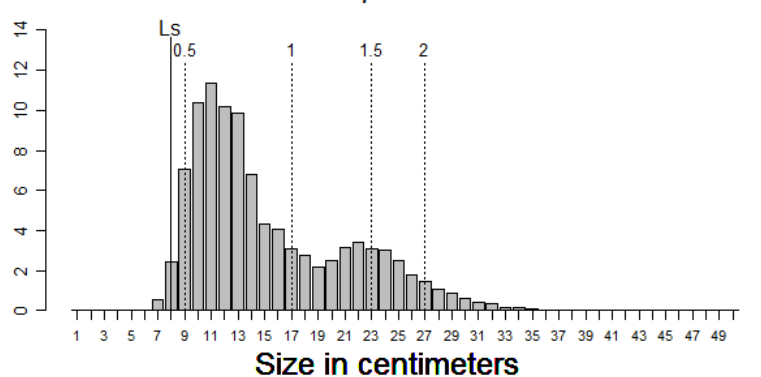

Mullus surmuletus

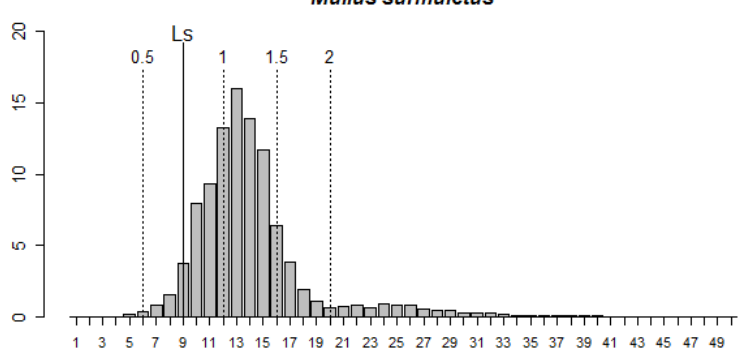

Solea solea

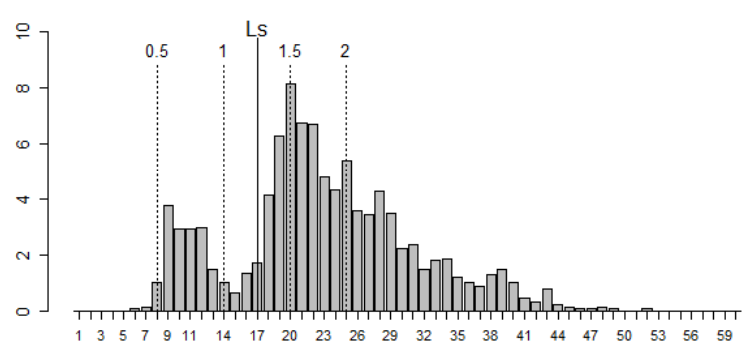

Zeus faber

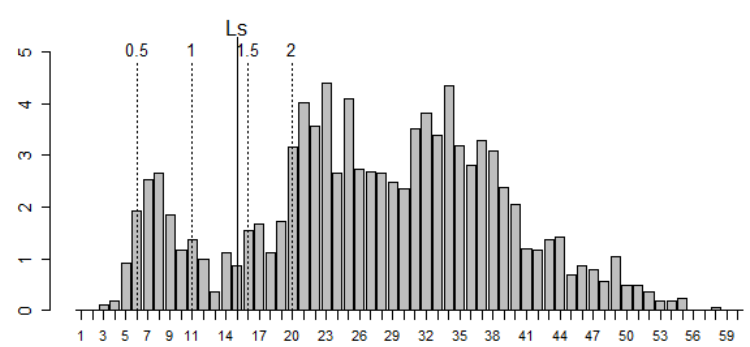

Fig. S2 continued: Size structure of the lasts nine species (in alphabetical order) sampled by EVHOE surveys between 1987 and 2009 , all year pooled. Solid line (i.e. $L_{s}$ ) represents the mean level of truncation that was applied for each species. All individuals below $L_{s}$ were removed before mean weight calculation. Dotted lines represent the age at size of species (i.e. 0,5 year / 1 year / 1,5 years and 2 years). 


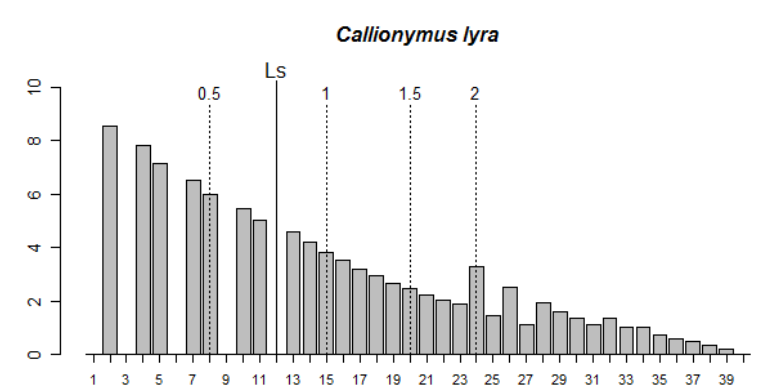

Conger conger

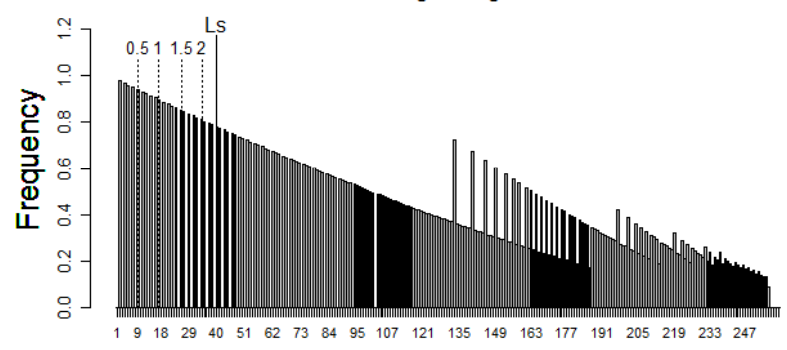

Lepidorhombus whiffiagonis

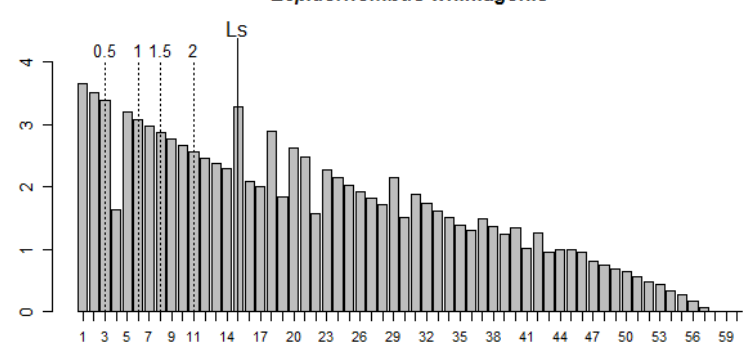

Chelidonichthys cuculus

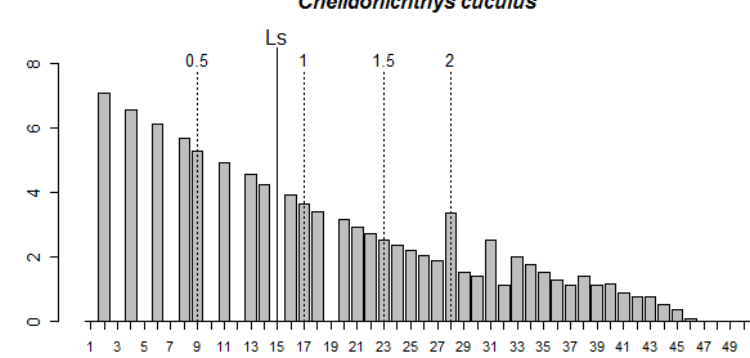

Dicentrarchus labrax

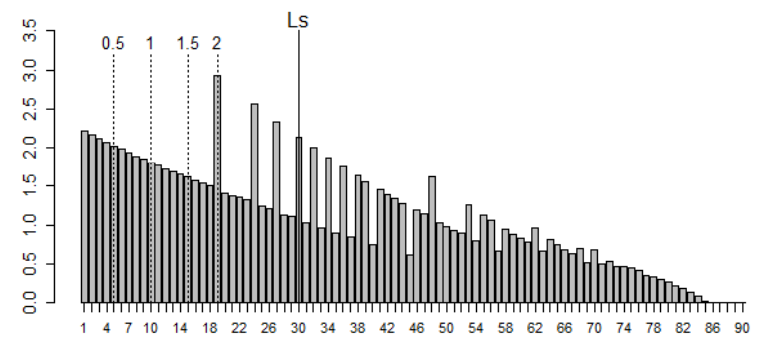

Lophius budegassa

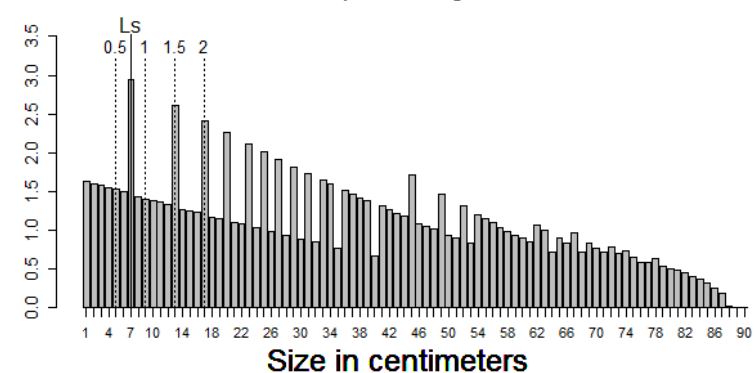

Chelidonichthys gurnardus

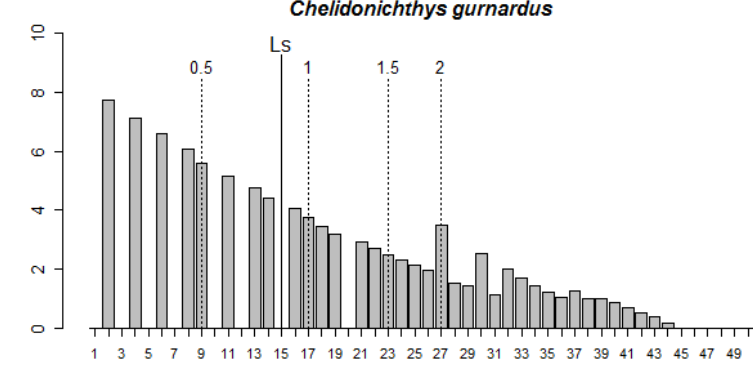

Dicologlossa cuneata

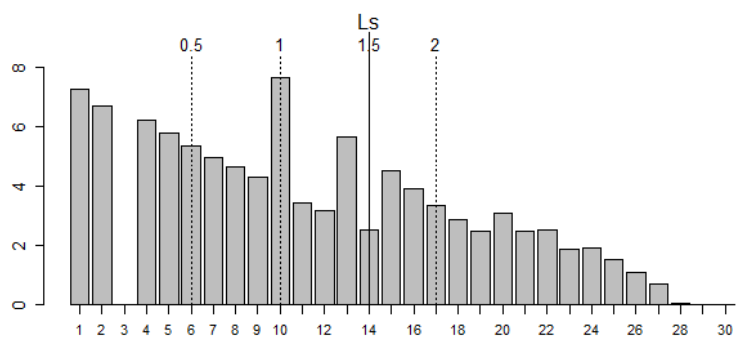

Lophius piscatorius

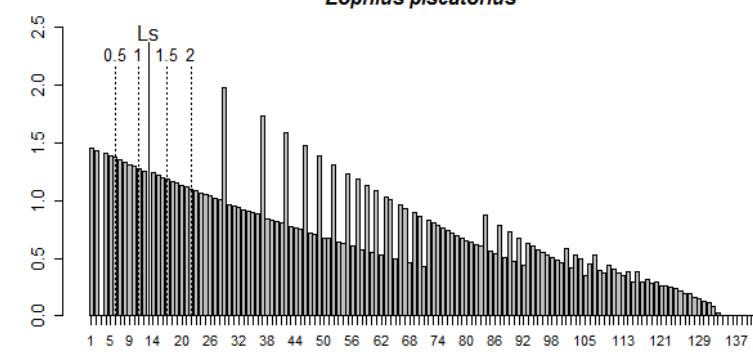

Fig. S3: Size structure of the firsts nine species (in alphabetical order) populations at equilibrium. Solid line (i.e. $L_{s}$ ) represents the mean level of truncation that was applied for each species. All individuals below $L_{s}$ were removed before mean weight calculation. Dotted lines represent the age at size of species (i.e. 0,5 year / 1 year / 1,5 years and 2 years). 


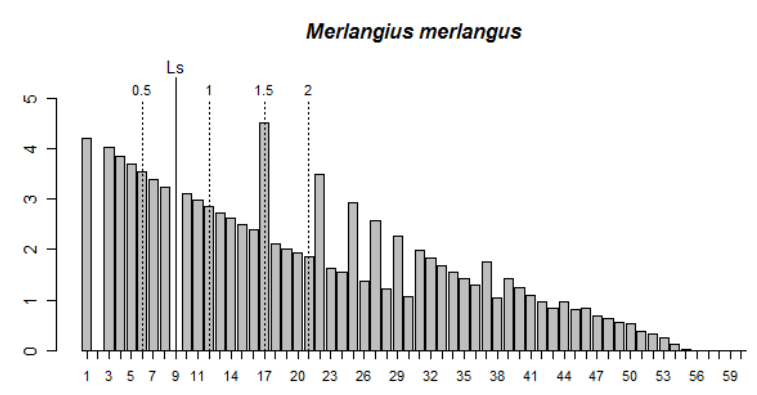

Phycis blennoides

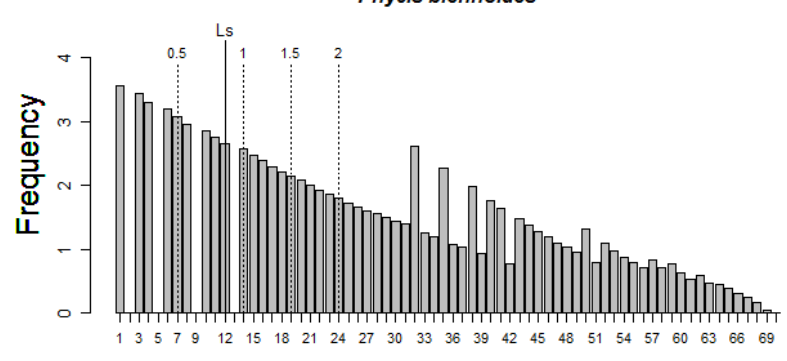

Trachurus trachurus

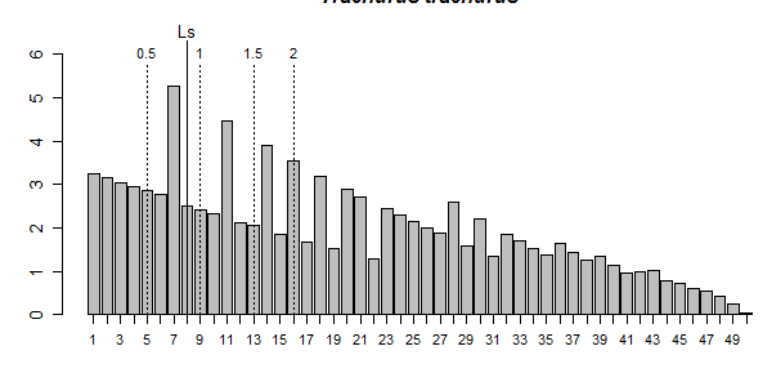

Merluccius merluccius

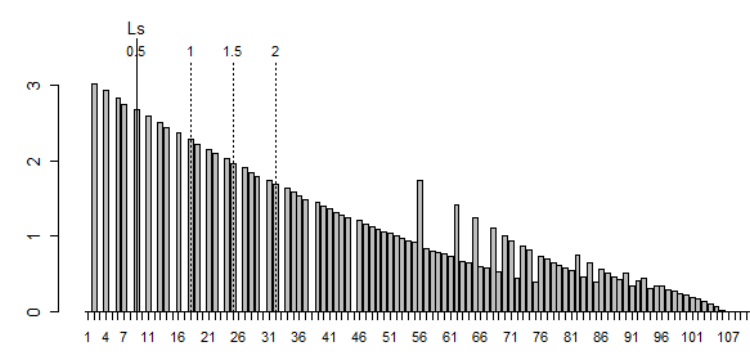

Scyliorhinus canicula

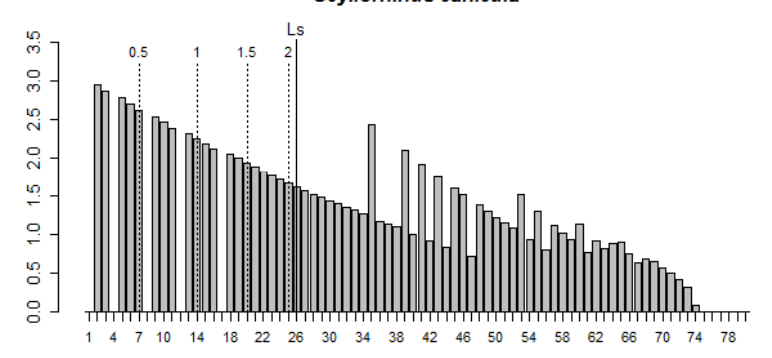

Trisopterus luscus

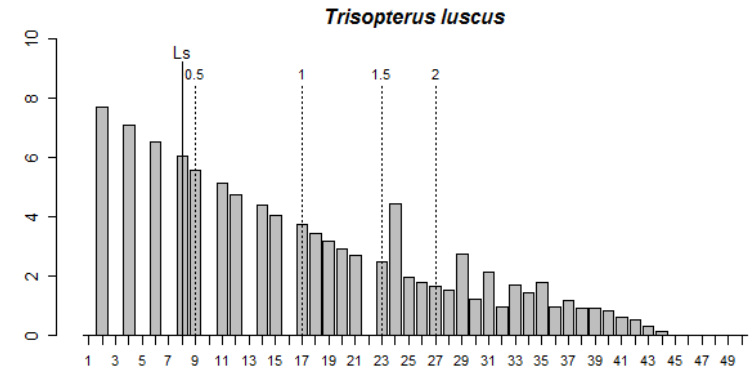

Mullus surmuletus

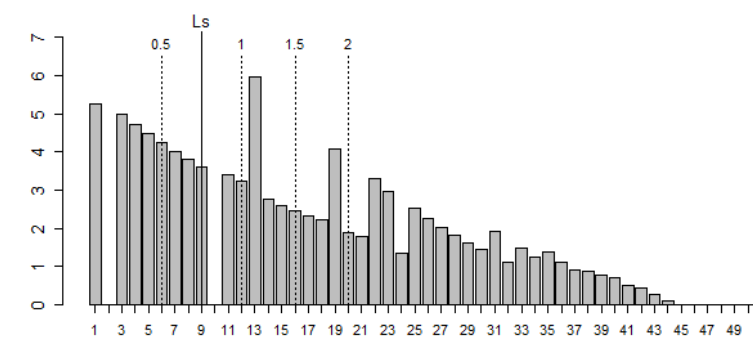

Solea solea

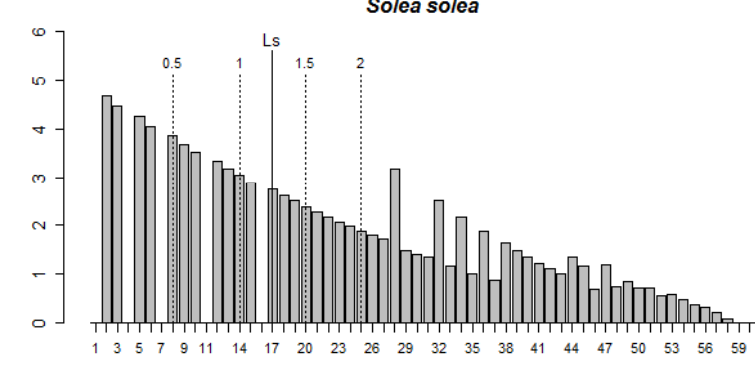

Zeus faber

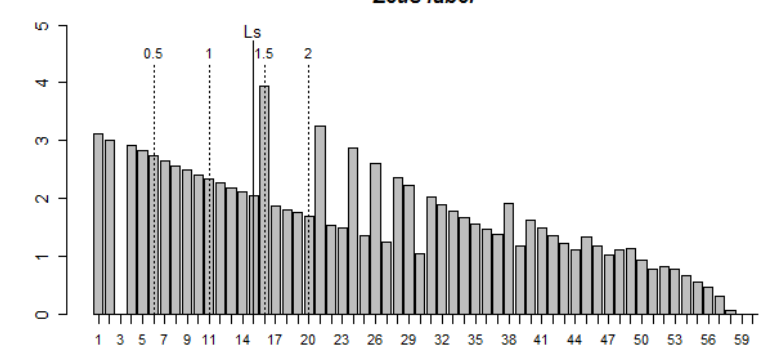

Fig. S3 continued: Size structure of the lasts nine species (in alphabetical order) populations at equilibrium. Solid line (i.e. $L_{s}$ ) represents the mean level of truncation that was applied for each species. All individuals below $L_{s}$ were removed before mean weight calculation. Dotted lines represent the age at size of species (i.e. 0,5 year / 1 year / 1,5 years and 2 years). 